\title{
Enhanced energy storage performance of (1-x)(BCT-BMT)-xBFO lead-free relaxor ferroelectric ceramics in a broad temperature range
}

Mengxing $\mathrm{Xu}^{1,3}$, Biaolin Peng ${ }^{1,3 *}$, Jinian $\mathrm{Zhu}^{2}$, Laijun Liu ${ }^{1 *}$, Wenhong Sun ${ }^{3 *}$, Glenn J.T. Leighton ${ }^{1}$, Christopher Shaw ${ }^{1}$, Nengneng Luo ${ }^{1}$, Qi Zhang ${ }^{1}$

${ }^{1}$ School of Aerospace, Transport and Manufacturing, Cranfield University, Cranfield, Bedfordshire, MK43 0AL, United Kingdom

${ }^{2}$ State Key Laboratory of Nickel and Cobalt Resources Comprehensive Utilization, Jinchang, Gansu, 737100, China

${ }^{3}$ Center on Nanoenergy Research, School of Physical Science \& Technology, Guangxi University, Nanning 530004, China

*Correspondence to: pengbL8@126.com, 1j1iu2@163.com,20180001@,gxu.edu.cn 
Abstract: Relaxor ferroelectrics with high energy storage performances are very attractive for modern applications in electronic devices and systems. Here, it is demonstrated that large energy densities $\left(0.52 \sim 0.58 \mathrm{~J} / \mathrm{cm}^{3}\right)$ simultaneously with high efficiencies $(76 \% \sim 82 \%)$ and thermal stabilities (the variations of efficiencies: $7 \%$ from 323 to $423 \mathrm{~K}$ ) have been achieved in the lead-free (1-x)(BCTBMT)- $x$ BFO relaxor ferroelectric ceramics prepared using a conventional solid-state reaction method. Large dielectric breakdown strengths and great relaxor dispersions around the dielectric peaks are responsible for the excellent energy storage performances. The energy storage performance of asprepared ceramics at high BFO doping amount $(x=0.06$ and 0.07$)$ was deteriorated seriously due to the decrease of dielectric breakdown strengths. However, they could be greatly improved when aged, since the operable electric field was significantly enhanced from $10 \mathrm{kV} / \mathrm{cm}$ of as-prepared samples to $100 \mathrm{kV} / \mathrm{cm}$ of aged samples due to the reduced concentration of oxygen vacancies during the aging process. The excellent energy storage performance may make them attractive materials for applications in energy storage systems in a broad temperature range.

Keywords: energy storage; BCT-BMT; relaxor; aging 


\section{Introduction}

Recently, with the development of electronic, information and technology toward miniaturization, dielectric capacitors have aroused widespread interests due to the high power density, extremely high charge/discharge speed $(<1 \mu \mathrm{s})^{(1-3)}$, low cost, long cycling life, high thermal and mechanical stability compared with linear dielectric polymer materials ${ }^{(2,4)}$. For ferroelectric (FE) materials, the most of energy charged is dissipated during the depolarization process because of the large remnant polarization, and only a small portion can be released ${ }^{(5)}$, leading to a low energy storage efficiency. Therefore, they are not good candidates for energy storage applications. For antiferroelectric (AFE) materials, they are unable to withstand hundreds of charge-discharge cycles because of the appearance of some fatal microcracks induced by large phase change stress between the AFEs and the FEs. Like wisely, they are not suitable for energy storage applications, neither ${ }^{(\sigma)}$. For relaxor ferroelectrics, the high energy storage density, high energy storage efficiency and long charge-discharge cycling life altogether make them be more potential for applications in energy storage systems ${ }^{(7,8)}$.

The research on the energy storage effect of relaxor ferroelectric materials mainly focuses on leadbased ceramics and their thin films, such as the $\mathrm{Pb}\left(\mathrm{Mg}_{1 / 3} \mathrm{Nb}_{2 / 3}\right) \mathrm{O}_{3}-\mathrm{PbTiO}_{3}\left(0.47 \mathrm{~J} / \mathrm{cm}^{3} \text { at } 70 \mathrm{kV} / \mathrm{cm}\right)^{(9)}$, the $\quad 0.2 \mathrm{~Pb}\left(\mathrm{Mg}_{1 / 3} \mathrm{Nb}_{2 / 3}\right) \mathrm{O}_{3}-0.8 \mathrm{~Pb}\left(\mathrm{Sn}_{0.36} \mathrm{Ti}_{0.64}\right) \mathrm{O}_{3} \quad\left(0.85 \quad \mathrm{~J} / \mathrm{cm}^{3} \text { at } 70 \mathrm{kV} / \mathrm{cm}\right)^{(10)}$ and the $\mathrm{Pb}_{0.97} \mathrm{La}_{0.02} \mathrm{Zr}_{0.8} \mathrm{Sn}_{0.145} \mathrm{Ti}_{0.055} \mathrm{O}_{3}\left(4.38 \mathrm{~J} / \mathrm{cm}^{3}\right.$ at $\left.230 \mathrm{kV} / \mathrm{cm}\right)$ ceramics ${ }^{(11)}$, the $\mathrm{Pb}\left(\mathrm{Nb}_{0.04} \mathrm{Zr}_{0.384} \mathrm{Ti}_{0.576}\right) \mathrm{O}_{3}$

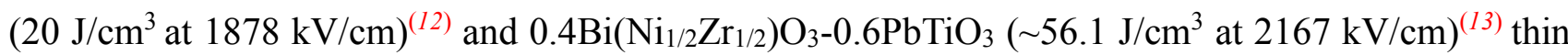
film, etc. Under the response of the European "RoHS/WEEE" environmental and health protection directive, the uses of lead-based relaxor ferroelectric materials will be restricted because of the strong toxicity of lead. Thus, it is imperative to develop environment-friendly lead-free materials. So far, many new lead-free materials have been reported and great progress in the energy storage performance 
has been made ${ }^{(14,15)}$. For example, some ceramics or thin films with large energy storage density have been obtained, such as $0.95 \mathrm{~J} / \mathrm{cm}^{3}$ in the $0.82\left[0.92 \mathrm{Bi}_{0.5} \mathrm{Na}_{0.5} \mathrm{TiO}_{3}-0.08 \mathrm{BaTiO}_{3}\right]-0.08 \mathrm{SrZrO}_{3}-$ $0.10 \mathrm{NaNbO}_{3}$ ceramic at $110 \mathrm{kV} / \mathrm{cm}^{(16)}, 1.5 \mathrm{~J} / \mathrm{cm}^{3}$ in the $0.94 \mathrm{~K}_{0.5} \mathrm{Na}_{0.5} \mathrm{NbO}_{3}-0.06 \mathrm{Sr}\left(\mathrm{Zn}_{1 / 3} \mathrm{Nb}_{2 / 3}\right) \mathrm{O}_{3}$ ceramic at $175 \mathrm{kV} / \mathrm{cm}^{(17)}$, as well as $42.9 \mathrm{~J} / \mathrm{cm}^{3}$ in the $0.89 \mathrm{Na}_{0.5} \mathrm{Bi}_{0.5} \mathrm{TiO}_{3}-0.06 \mathrm{BaTiO}_{3}-0.05 \mathrm{BiFeO}_{3}$ thin film at $1720 \mathrm{kV} / \mathrm{cm}^{(18)}$ and $51 \mathrm{~J} / \mathrm{cm}^{3}$ in the $0.4 \mathrm{Bi}_{1.05} \mathrm{Fe}_{0.995}-\mathrm{Mn}_{0.005} \mathrm{O}_{3}-0.6 \mathrm{SrTiO}_{3}$ thin film at 3600 $\mathrm{kV} / \mathrm{cm}^{(19)}$, etc. Moreover, some ceramics with high efficiency $(\eta)$ have also been synthesized to satisfy the needs of practical applications in energy storage, such as $93.3 \%$ in $0.8 \mathrm{BaTiO}_{3}-0.2 \mathrm{BiYbO}_{3}$ ceramic at $100 \mathrm{kV} / \mathrm{cm}^{(20)}, 87.7 \%$ in the $\mathrm{ZnO}-\mathrm{Li}_{2} \mathrm{O}$ modified $\mathrm{Ba}_{0.4} \mathrm{Sr}_{0.6} \mathrm{TiO}_{3}$ ceramics at $198.8 \mathrm{kV} / \mathrm{cm}^{(21)}$ and $90 \%$ in the BT@ST ceramic at $47 \mathrm{kV} / \mathrm{cm}^{(22)}$. In addition to large $W_{\text {energy }}$ and $\eta$, good thermal stability should also be an important parameter required for practical applications in energy storage. However, to our knowledge, the thermal stability of lead-free materials has not been greatly improved. For example, although a large $W_{\text {energy }}\left(\sim 0.81 \mathrm{~J} / \mathrm{cm}^{3}\right)$ with a high efficiency $(\eta>94 \%)$ was obtained in $0.86 \mathrm{BaTiO}_{3}$ $0.14 \mathrm{Bi}\left(\mathrm{Zn}_{0.5} \mathrm{Ti}_{0.5}\right) \mathrm{O}_{3}$ ceramic ${ }^{(23)}$, the thermal stability (the variations of efficiency: $17 \%$ ) is not high enough to meet practical applications.

Previous research work has revealed that a near-plateau relative permittivity $(835 \pm 40)$ in a broad temperature range of $65^{\circ} \mathrm{C}-550^{\circ} \mathrm{C}$ can be obtained in $0.5 \mathrm{Ba}_{0.8} \mathrm{Ca}_{0.2} \mathrm{TiO}_{3}-0.5 \mathrm{BiMg}_{0.5} \mathrm{Ti}_{0.5} \mathrm{O}_{3}$ lead-free ferroelectric ceramics ${ }^{(24,25)}$. This result indicates that it could be a potential candidate in energy storage. It has been well-known that the $\mathrm{BiFeO}_{3}$ multiferroic has the highest theoretical spontaneous polarization $\left(P>100 \mu \mathrm{C} / \mathrm{cm}^{2}\right)$ in ferroelectrics as reported so $\mathrm{far}^{(26)}$. Therefore, it has often been considered as a favoring dopant to enhance the performance of ferroelectrics.

In this work, large energy densities $\left(0.52 \sim 0.58 \mathrm{~J} / \mathrm{cm}^{3}\right)$ simultaneously with high efficiencies $(76 \% \sim$ 82\%) and thermal stabilities (the variations of efficiencies: $7 \%$ from 323 to $423 \mathrm{~K}$ ) were reported in 
the lead-free $\mathrm{BiFeO}_{3}$-doped $0.5 \mathrm{Ba}_{0.8} \mathrm{Ca}_{0.2} \mathrm{TiO}_{3}-0.5 \mathrm{BiMg}_{0.5} \mathrm{Ti}_{0.5} \mathrm{O}_{3}$ relaxor ferroelectric ceramics prepared using a conventional solid-state reaction method. The excellent energy storage performances are attributed to the large dielectric breakdown strengths and great relaxor dispersion around the dielectric peaks. Moreover, it is also found that the aging has a great impact on the enhancement of the energy storage performance of ceramics with a higher BFO doping amount ( $x=0.06$ and 0.07$)$. These breakthroughs make the materials very attractive for practical applications in energy storage systems.

\section{Experimental procedures}

$\mathrm{BiFeO}_{3}$-doped $0.5 \mathrm{Ba}_{0 .} \mathrm{Ca}_{0.2} \mathrm{TiO}_{3}-0.5 \mathrm{BiMg}_{0.5} \mathrm{Ti}_{0.5} \mathrm{O}_{3}$ (abbreviated as $(1-x)(\mathrm{BCT}-\mathrm{BMT})-x \mathrm{BFO}$, where $x$ $=0.0,0.01,0.02,0.03,0.04,0.05,0.06$ and 0.07$)$ ceramics were fabricated using $\mathrm{BaCO}_{3}(99 \%), \mathrm{CaCO}_{3}$ (99\%), $\mathrm{Bi}_{2} \mathrm{O}_{3}(99 \%), \mathrm{TiO}_{2}(98 \%), \mathrm{MgO}(98.5 \%)$ and $\mathrm{Fe}_{2} \mathrm{O}_{3}(99 \%)$ as raw materials. $\mathrm{Bi}_{2} \mathrm{O}_{3}$ and $\mathrm{MgO}$ with $3 \mathrm{wt} \%$ excess were added because of the volatility of $\mathrm{Bi}$ and $\mathrm{Mg}$. The raw materials were milled in a nylon tank with the zirconia balls as media in ethanol for $12 \mathrm{~h}$. The dried slurries were calcined at $900{ }^{\circ} \mathrm{C}$ for $6 \mathrm{~h}$ and re-milled for another $12 \mathrm{~h}$ to reduce the component segregation. After dried and recalcined at $910^{\circ} \mathrm{C}$ for $6 \mathrm{~h}$, the powders were milled and dried again to obtain homogeneous powders. The powders were subsequently compacted into green pellets with a diameter of $8 \mathrm{~mm}$ and they were pressed isostatically at $260 \mathrm{MPa}$. All pellets were sintered at $1200{ }^{\circ} \mathrm{C}$ for $6 \mathrm{~h}$ with a heating rate of 3 ${ }^{\circ} \mathrm{C} / \mathrm{min}$ in air, and then cooled to $800{ }^{\circ} \mathrm{C}$ with a cooling rate of $5{ }^{\circ} \mathrm{C} / \mathrm{min}$, and finally cooled to room temperature naturally. To reduce the loss of bismuth and magnesium elements during the sintering process, all pellets were buried in the powders with the same composition.

The microstructures of ceramics were examined by the field emission scanning electron microscopy (FE-SEM, SU8220, Hitachi Co). The crystal structures of ceramics were analyzed by the X-ray 
diffraction (XRD, PANalytical X'Pert PRO) using $\mathrm{Cu}$ K $\alpha$ radiation $(\lambda=1.5406 \AA ̊$ ). Room temperature Raman Spectra were carried out by the Laser Micro Raman system (DXR, Thermo Fisher Scientific). For the measurements of electrical properties, silver paste was painted both sides on the polished ceramics as the electrodes and fired at $600{ }^{\circ} \mathrm{C}$ for $30 \mathrm{~min}$. The temperature dependence of the dielectric permittivity $\left(\varepsilon_{r}\right)$, dielectric loss $(\tan \delta)$ and impedance of ceramics were measured using an impedance analyzer (HP 4192A). The hysteresis loops between polarizations and electric fields $(P-E$ loops) at 1 Hz were obtained using a ferroelectric analyzer (TF-2000, AixACCT, Aachen).

\section{Results and analysis}

\subsection{Structure and morphology}

Fig. 1a) shows the X-ray diffraction (XRD) patterns of the BFO-doped BCT-BMT ceramics. All samples exhibited good crystallinities and pure perovskite structures with the coexistence of orthorhombic and tetragonal phases. When the amount of BFO increased, the diffraction peaks shifted slightly towards the left, as shown in the enlarged parts in Fig. 1b). The intensity of the $(10 \overline{1})_{O},(11 \overline{1})_{O}$ and $(020)_{O}$ peaks gradually decreased, while the intensity of the $(002)_{T}$ peak gradually increased, indicating that the rate of the orthogonal phase to tetragonal phase decreased. As $x>0.04$, the diffraction peaks shifted back slightly toward the right, and the intensity of the $(10 \overline{1})_{O},(11 \overline{1})_{O}$ and $(020)_{O}$ peaks gradually increased but the intensity of the $(002)_{T}$ peak gradually decreased, indicating that the rate of the phase change from orthogonal to tetragonal phase increased. The above results indicate that the compositions of samples are all located at the MPB.

Fig. 1c) shows the Raman spectra of the BFO-doped BCT-BMT ceramics at room temperature. There are no new peaks on the Raman spectra, indicating that no new phases generate with the addition of 
BFO. All spectra were fitted and deconvoluted into individual Guassian components to obtain the information of each peak. These Raman peaks can be divided into three main regions, including Asite, $\mathrm{B}-\mathrm{O}$ bond and the $\mathrm{BO}_{6}$ Octahedra. The mode of $185 \mathrm{~cm}^{-1}$ is related to the $\mathrm{A}-\mathrm{O}$ vibrations $\left(\mathrm{A}: \mathrm{Ba}^{2+}\right.$, $\mathrm{Ca}^{2+}$ and $\mathrm{Bi}^{3+}$ cations $)^{(27)}$. The modes of $200 \mathrm{~cm}^{-1}$ and $315 \mathrm{~cm}^{-1}$ are related to $\mathrm{A}_{1}\left(\mathrm{TO}_{2}\right)_{O / T}$ and $\mathrm{E}\left(\mathrm{TO}_{3}\right) / \mathrm{B}_{1 O / T}$, respectively ${ }^{(25)}$. The mode of $515 \mathrm{~cm}^{-1}$ is related to $\mathrm{A}_{1}\left(\mathrm{TO}_{3}\right) / \mathrm{E}(\mathrm{TO})_{T}$ caused by the O-TiO symmetric stretching vibrations. The mode of $718 \mathrm{~cm}^{-1}$ is related to the $\mathrm{A}_{1}\left(\mathrm{LO}_{3}\right) / \mathrm{E}\left(\mathrm{LO}_{4}\right)_{T}$ activated by the structural distortion of the lattice ${ }^{(28)}$. The mode of $780 \mathrm{~cm}^{-1}$ is related to the $\mathrm{A}_{1} \mathrm{~g}$ (octahedral breathing mode), which is symmetrical and Raman inactive in A-site doped $\mathrm{BaTiO}_{3}$-based ceramics but asymmetric and Raman active in one of B-site doped ${ }^{(29)}$. It should be noted that the new band mode on the Raman spectra represents the high-pressure Raman spectra of Ba-based relaxor ferroelectric ceramic. The evolutions of the band center position, full width at half maximum (FWHM) and height were quantitatively extracted, as shown in Fig. 1d) and Fig. S1. It is observed that the FWHM of the $\mathrm{A}_{1}\left(\mathrm{TO}_{3}\right) / \mathrm{E}(\mathrm{TO})_{T}$ mode increases sharply with the increasing BFO and reaches a maximum value at $x$ $=0.03$, but it decreases sharply with further increasing BFO and gets a minimum value at $x=0.04$. The FWHM of $\mathrm{E}\left(\mathrm{TO}_{3}\right) / \mathrm{B}_{10 / T}$ mode increases sharply with the increase of $\mathrm{BFO}$ and reaches a maximum value at $x=0.04$, but it decreases sharply with further increasing BFO. These results indicate that the rate of the orthogonal phase to tetragonal phase changed significantly around the contents of $x=3$ and 4, consistent with the results of XRD analysis. Moreover, it is found that the phase transition from orthogonal to tetragonal also plays an important role on the dielectric properties and energy storage performance of ceramics, as shown by the subsequent part of the paper.

Fig. 2 shows the surface SEM images of BFO-doped BCT-BMT ceramics after thermal etching at 1100 ${ }^{\circ} \mathrm{C}$ for $4 \mathrm{~h}$. All samples were well crystallized and exhibit dense microstructures. With increasing $x$, 
grain boundaries of samples gradually turned from angular into circular arc, due to the decreasing melting point as increasing the doping amount. For $x=0$ to 0.04 , especially $x=0.04$ (see Fig. 2e)), some small particles (ceramic powders left during the polishing process) dwelled on the surface of samples. They disappeared with increasing $x$, as shown in Fig. 2f) - 2h). The insets in Fig. 2a) - 2h) show the statistic distributions of the grain sizes in ceramics calculated from Fig S2. With increasing $x$, the average grain size of samples increased gradually from $7.04 \mu \mathrm{m}$ at $x=0$ to $13.60 \mu \mathrm{m}$ at $x=0.07$, indicating a decreasing melting point in the BFO-doped BCT-BMT ceramics.

\subsection{Dielectric properties}

Fig. $\mathbf{S 3}$ shows the temperature dependences of the dielectric permittivities $(\varepsilon(T))$ and the dielectric losses $(\tan \delta(T))$ of the BFO-doped BCT-BMT ceramics, including the prepared and aged (3 days in air). The dielectric peaks of samples can be clearly observed at high enough frequencies such as $1 \mathrm{MHz}$, however, they gradually disappear with the decreasing frequency because of the effects of some defects such as the oxygen vacancies and space charges, etc., especially for those of aged samples, as shown in Fig. S3b), S3d), S3f), S3h), S3j), S3I), S3n) and S3p). The dielectric permittivities of all as-prepared samples at room temperature change slightly, indicating a negligible effect of the BFO doping. All samples also behavior as dielectric relaxors, namely the $T_{m}$ and the $T_{m}^{\delta}$ shift towards higher temperature with increasing frequency ${ }^{(30,31)}$. As the temperature increases to the $T_{m}$, the peak values of the dielectric permittivities of all samples almost unchanged ( 1600 at $1 \mathrm{MHz})$. The dielectric peaks become more and more diffused and broadened with the increasing content of BFO. The dielectric relaxation behavior of samples around the peaks can be described by the Lorentz-type empirical relation $^{(32,33)}, \varepsilon_{A} / \varepsilon=1+\left(T-T_{A}\right)^{2} / 2 \delta_{A}^{2}$, where $T_{A}\left(T_{A} \neq T_{m}\right)$ and $\varepsilon_{A}$ are the parameters that define 
the temperature of the dielectric peak and the extrapolated value of $T=T_{A}$, respectively. The parameter $\delta_{A}$ is frequency independent at high enough frequencies and represents the relaxor diffuseness of the dielectric peak. The larger $\delta_{A}$ is, the greater the relaxation is. Table 1 lists the parameter $\delta_{A}$ of the $(1-x)($ BCT-BMT $)-x$ BFO ceramics including the as-prepared and aged ceramics at $1 \mathrm{MHz}$. The $\delta_{A}$ of as-prepared samples with $x=0$ to 0.04 is smaller than that of corresponding aged samples, whereas the $\delta_{A}$ of as-prepared sample with $x=0.05$ is larger than that of corresponding aged sample. The minimum parameter $\delta_{A}$ obtained around the dielectric peak of $x=0.04$ is 106.58 which is close to that (103.6) of the prototypical relaxor $\mathrm{Pb}\left(\mathrm{Mg}_{1 / 3} \mathrm{Nb}_{2 / 3}\right) \mathrm{O}_{3}$ ceramics, indicating that all samples exhibit great relaxor dispersion ${ }^{(33)}$.

\subsection{Energy Storage}

Fig. 3 and Fig. $\mathbf{S} 4$ show the $P-E$ loops of the (1-x)(BCT-BMT)- $x$ BFO as-prepared and aged ceramics at selected electric fields and room temperature. To avoid dielectric breakdown, conservative electric field are applied to samples. As the electric field increases, all $P-E$ loops of samples $(x=0$ to 0.05$)$ including the as-prepared and aged exhibit slim loops with four week $I-E$ peaks, as shown by the arrows in the insets of Fig.3 and Fig.S4, which are ascribed to the pinning and depinning of the domains walls by defects such as bismuth and oxygen vacancies. Bad looking $P-E$ loops (see the ellipses in Fig. 3c) and Fig.3e) and their right lower corner insets) of as-prepared samples of $x=0.06$ and 0.07 are obtained under a very low operable electric field (only $10 \mathrm{kV} / \mathrm{cm}$ ), indicating a low dielectric breakdown strength and a high leakage current. However, for the aged samples of $x=0.06$ and 0.07 , the operable electric field can be improved obviously with the increase of aging time, as shown by the Fig. S7c) to S7h). Meanwhile, the $P-E$ loops become more and more slim, indicating an 
enhanced dielectric breakdown strength and a depressed leakage current. Good looking $P-E$ loops can be achieved when they were aged for a week and then heated at $300^{\circ} \mathrm{C}$ for $30 \mathrm{~min}$, as shown in Fig. 3d) and Fig.3f). Previous research works have pointed that oxygen vacancies $\left(V_{O}^{\bullet \bullet}\right)^{\prime}$ can be generated during the sintering process ${ }^{(34)}$, and tend to deteriorate the dielectric breakdown strength. However, they can also be eliminated under moderate conditions. For the aged samples of $x=0.06$ and 0.07 , the residual oxygen vacancies prefer to be transformed into $O_{O}$ and left holes by the environmental oxygen when aged for a time, as shown by the equation (2). These holes can be neutralized by electrons in the BFO-doped BCT-BMT ceramics, as shown in the equation (3), resulting in a reduction of oxygen vacancies. Accordingly, the recombination of electrons and holes leads to an improvement of insulating properties (see the larger $Z^{\prime \prime}$ in the left upper corner insets of Fig. 3c) and Fig.3e) in the aged samples, especially for $x=0.06$ and 0.07 . Thus, an enhanced dielectric breakdown strength was achieved, leading to an improved operable electric field with the increase of aging time.

$$
\begin{aligned}
& \frac{1}{2} \mathrm{O}_{2}+V_{O}^{\bullet \bullet} \rightarrow O_{O}+2 \mathrm{~h}^{\bullet} \\
& 2 \mathrm{Fe}^{3+} \stackrel{M g^{2+}}{\longrightarrow} 2 \mathrm{Fe}_{M g}^{\bullet}+2 e^{\prime}
\end{aligned}
$$

Fig. S6 shows the AC conductivity $\left(\sigma_{a c}\right)$ of $(1-x)(\mathrm{BCT}-\mathrm{BMT})-x \mathrm{BFO}$ as-prepared and aged ceramics of $x=0$ to 0.07 at selected temperatures. For aged samples, as the temperature decreases, the magnitude of the decrease of the $\sigma_{a c}$ is large than that of as-prepared samples, especially the samples with a higher doping content, indicating that the samples become more insulative. The room temperature dielectric constant $(\varepsilon)$ and dielectric loss $(\tan \delta$ ) as a function of frequency of as-prepared, aged and oxidized samples (annealed in a tube furnace and in oxygen) are illustrated in Fig. S7. It can be found that the $\varepsilon$ values of aged and oxidized samples of $x=0.06$ and 0.07 are higher than that of as-prepared samples at low frequencies, and the increased magnitude of $\varepsilon$ in oxidized samples is higher than that in aged 
samples. These results indicate that the reduced concentration of oxygen vacancies plays a key role in the enhancement of the dielectric breakdown strength and the improvement of the operable electric field of the (1-x)(BCT-BMT)- $x$ BFO ceramics, especially for the $x=0.06$ and 0.07 .

The recoverable energy density ( $W_{\text {energy }}$ ) of a dielectric-based material is estimated from the $P$ - $E$ loops and calculated with the following equation

$$
W_{\text {energy }}=\int_{P_{r}}^{P_{\max }} E d P, \quad 0 \leq E \leq E_{\max }
$$

where $E$ is the applied electric field that causes variation in the electric polarization $P, P_{r}$ the remnant polarization, and $P_{\max }$ the maximum polarization under the applied field ${ }^{(2,3,35)}$. According to equation (4), materials simultaneously possessing smaller $P_{\mathrm{r}}$, larger $P_{\max }$, and higher dielectric breakdown strength are more favorable for energy storage. For practical applications, in addition to a large $W_{\text {energy, }}$ a high energy storage efficiency $(\eta)$ is also desired. The $\eta$ is defined as the ratio of the discharging (output) energy to the charging (input) energy

$$
\eta=\frac{W_{\text {energy }}}{W_{\text {energy }}+W_{\text {loss }}}
$$

where $W_{\text {loss }}$ is the energy loss density, calculated by the numerical integration of the closed area of the hysteresis loops ${ }^{(36)}$. The electric field dependence of $W_{\text {energy }}, W_{\text {loss }}$ and $\eta$ of BFO-doped BCT-BMT based ceramics as-prepared and corresponding aged at selected electric fields are shown in Fig. 4a), 4b), 4c) and 4 d). It can be seen that the $W_{\text {energy, }} W_{\text {loss }}$ and $\eta$ values of all samples increase with the increasing applied electric field. For as-prepared samples of $x=0$ to 0.05 , the $W_{\text {energy values change }}$ from 0.53 to $0.58 \mathrm{~J} / \mathrm{cm}^{3}$ at $100 \mathrm{kV} / \mathrm{cm}$, indicating that the BFO doping amount has a weak effect on the performance of the energy storage. However, for as-prepared samples of $x=0.06$ and 0.07 , the performance of the energy storage is very bad, due to the low dielectric breakdown electric field. When they were aged for a week and then heated at $300{ }^{\circ} \mathrm{C}$ for $30 \mathrm{~min}$, the energy storage performance is 
improved significantly, due to the increased dielectric breakdown electric field as shown in Fig. 4 b)

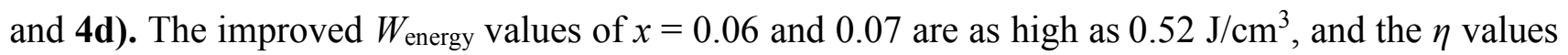
are $75.7 \%$ and $79.6 \%$, respectively. The maximum $\eta$ of as-prepared and aged samples are $82.21 \%(x$ $=0.05)$ and $81.97 \%(x=0.05)$ at $100 \mathrm{kV} / \mathrm{cm}$, respectively. They are better than those of other bulk ceramic systems: $\mathrm{BiFeO}_{3}-\mathrm{BaTiO}_{3}-\mathrm{Ba}\left(\mathrm{Mg}_{1 / 3} \mathrm{Nb}_{2 / 3}\right) \mathrm{O}_{3}(\eta \sim 75 \%, 125 \mathrm{kV} / \mathrm{cm})^{(37)}, 0.90\left(\mathrm{Bi}_{0.5} \mathrm{Na}_{0.5} \mathrm{TiO}_{3}-\right.$ $\left.\mathrm{BaTiO}_{3}\right)-0.10 \mathrm{NaTaO}_{3}(\eta \sim 74.8 \%, 100 \mathrm{kV} / \mathrm{cm})^{(38)}, 0.85\left(\mathrm{BaZr}_{0.2} \mathrm{Ti}_{0.8}\right) \mathrm{O}_{3}-0.15\left(\mathrm{Ba}_{0.7} \mathrm{Ca}_{0.3}\right) \mathrm{TiO}_{3}(\eta \sim 72 \%$, $170 \mathrm{kV} / \mathrm{cm})^{(6)}$ and $0.9 \mathrm{~Pb}\left(\mathrm{Mg}_{1 / 3} \mathrm{Nb}_{2 / 3}\right) \mathrm{O}_{3}-0.1 \mathrm{PbTiO}_{3}(\eta \sim 78.3 \%, 70 \mathrm{kV} / \mathrm{cm})^{(9)}$.

In order to further study the variation law of the energy density of the (1-x)(BCT-BMT)- $x$ BFO ceramics under the electric field, a functional expression is defined here:

$$
Q=\frac{W}{E_{x}}=\frac{\int_{0}^{D x} E d D}{E_{x}}=\frac{\left(\int_{0}^{P x} E d P\right)}{E_{x}}, 0 \leq E \leq E_{x} \leq E_{\max }
$$

$Q$ represents the energy storage density of the material under the unit electric field. The relationships between $Q$ and applied electric field are given in Fig. 4e) and $\mathbf{4 f}$ ). There is no obvious change in the $Q$ value of as-prepared samples. A maximum $Q$ value $\left(0.0058 \mathrm{~J} / \mathrm{cm}^{2} \cdot \mathrm{kV}\right)$ can be obtained for as-prepared samples at $x=0.01$ and 0.04 . However, when aged, the maximum $Q$ value is obtained only at $x=0.04$. Similar to the $W_{\text {energy }}$ and the $\eta$, the $Q$ value of the aged samples at $x=0.06$ and 0.07 have also been improved significantly, and they are $0.00524 \mathrm{~J} / \mathrm{cm}^{2} \cdot \mathrm{kV}$ and $0.00522 \mathrm{~J} / \mathrm{cm}^{2} \cdot \mathrm{kV}$, respectively.

The thermal stability of energy storage performance should also be considered for real capacitor applications. Fig. 5 shows the $P-E$ loops of the $(1-x)(B C T-B M T)-x$ BFO ceramics in a wide temperature range of $303-453 \mathrm{~K}$, which is measured at $80 \mathrm{kV} / \mathrm{cm}$, slightly lower than $100 \mathrm{kV} / \mathrm{cm}$ to protect the samples from being thermally destroyed. The insets of Fig. 5 summarize the temperature dependence of the $W_{\text {energy }}, W_{\text {loss }}, \eta$ and $Q$. It is found that the thermal stability of the energy storage performance first increases slightly with the increase of doping BFO content, and reaches the best at $x=0.04$, and 
then decreases slightly. For as-prepared sample at $x=0.04$, the $W_{\text {energy }}, \eta$ and $Q$ increase rapidly from room temperature $\left(0.39 \mathrm{~J} / \mathrm{cm}^{3}, 82 \%, 0.0048 \mathrm{~J} / \mathrm{cm}^{2} \cdot \mathrm{kV}\right)$ up to $383 \mathrm{~K}\left(0.45 \mathrm{~J} / \mathrm{cm}^{3}, 98 \%, 0.0057 \mathrm{~J} / \mathrm{cm}^{2} \cdot \mathrm{kV}\right)$ and then decreases slightly. Especially, the variation of $\eta$ from $323 \mathrm{~K}$ to $423 \mathrm{~K}$ is about within $7 \%$, as shown by the black and blue dot-solid line of the inset of Fig. 5, indicating good thermal stability. The good thermal stability may be related to the great relaxor dispersion as described in the dielectric properties. For aged samples, especially for those aged for a week and then heated at $300{ }^{\circ} \mathrm{C}$ for 30 min, not only the energy storage performances but also the thermal stabilities have also been improved significantly, as shown in Fig. 5g) and $\mathbf{5 h}$ ). All in all, the sample $x=0.04$ will be a very promising environmental-friendly material with high thermal stability for modern energy storage technology, especially in electronic and electric systems.

\section{Conclusion}

Large energy density $\left(0.52 \sim 0.58 \mathrm{~J} / \mathrm{cm}^{3}\right)$ simultaneously with high efficiency $(76 \% \sim 82 \%)$ and thermal stability (variation between $7 \%$ at $80 \mathrm{kV} / \mathrm{cm}$ from 323 to $423 \mathrm{~K}$ ) have been achieved in the lead-free $(1-x)($ BCT-BMT)-xBFO relaxor ferroelectric ceramics prepared using a conventional solidstate reaction method. The excellent energy storage performances were accomplished by the large dielectric breakdown strengths and great relaxor dispersion around the dielectric peaks. The energy storage performance of ceramics at high BFO doping amount $(x=0.06$ and 0.07$)$ can be improved significantly, due to the reduced concentration of oxygen vacancies during the aging process. The excellent energy storage performances may make them a promising environmental-friendly material for modern energy storage devices.

\section{Acknowledgments}


This work was supported by the National Natural Science Foundation of China (51402196、51602159), the Guangxi Natural Science Foundation (Grants 2016GXNSFCB380006, 2017GXNSFFA198015), and the Scientific Research Foundation of Guangxi University (Grant XTZ160530), the Opening Project of State Key Laboratory of Nickel and Cobalt Resources Comprehensive Utilization (201901), Bagui Rencai \& Bagui Xuezhe Funding (Grant C31200992001).

\section{References}

1. B. Chu, X. Zhou, K. Ren, B. Neese, M. Lin, Q. Wang, F. Bauer, Q. M. Zhang, A dielectric polymer with high electric energy density and fast discharge speed. Science 313, 334-336 (2006).

2. T. M. Correia, M. McMillen, M. K. Rokosz, P. M. Weaver, J. M. Gregg, G. Viola, M. G. Cain, G. L. Brennecka, A Lead-Free and High-Energy Density Ceramic for Energy Storage Applications. Journal of the American Ceramic Society 96, 2699-2702 (2013)10.1111/jace.12508).

3. Y. Zhao, X. Hao, Q. Zhang, Energy-storage properties and electrocaloric effect of $\mathrm{Pb}_{(1-}$ ${ }_{3 x / 2} \mathrm{La}_{\mathrm{x}} \mathrm{Zr}_{0.85} \mathrm{Ti}_{0.15} \mathrm{O}_{3}$ antiferroelectric thick films. ACS applied materials \& interfaces $\mathbf{6}, 11633-$ 11639 (2014); published online EpubJul 23 (10.1021/am502415z).

4. S. Kwon, W. Hackenberger, E. Alberta, E. Furman, M. Lanagan, Nonlinear dielectric ceramics and their applications to capacitors and tunable dielectrics. IEEE Electrical Insulation Magazine 27, 43-55 (2011).

5. X. Wang, Y. Zhang, X. Song, Z. Yuan, T. Ma, Q. Zhang, C. Deng, T. Liang, Glass additive in barium titanate ceramics and its influence on electrical breakdown strength in relation with energy storage properties. Journal of the European Ceramic Society 32, 559-567 
(2012)10.1016/j.jeurceramsoc.2011.09.024).

6. V. S. Puli, D. K. Pradhan, D. B. Chrisey, M. Tomozawa, G. L. Sharma, J. F. Scott, R. S. Katiyar, Structure, dielectric, ferroelectric, and energy density properties of $(1-x) \mathrm{BZT}-x \mathrm{BCT}$ ceramic capacitors for energy storage applications. Journal of Materials Science 48, 2151-2157 (2013)10.1007/s10853-012-6990-1).

7. L. E. Cross, Relaxorferroelectrics: An overview. Ferroelectrics 151, 305-320 (1994)10.1080/00150199408244755).

8. L. Jin, F. Li, S. Zhang, D. J. Green, Decoding the Fingerprint of Ferroelectric Loops: Comprehension of the Material Properties and Structures. Journal of the American Ceramic Society 97, 1-27 (2014)10.1111/jace.12773).

9. T. F. Zhang, X. G. Tang, Q. X. Liu, Y. P. Jiang, X. X. Huang, Q. F. Zhou, Energy-storage properties and high-temperature dielectric relaxation behaviors of relaxor ferroelectric $\mathrm{Pb}\left(\mathrm{Mg}_{1 / 3} \mathrm{Nb}_{2 / 3}\right) \mathrm{O}_{3}-\mathrm{PbTiO}_{3}$ ceramics. Journal of Physics D: Applied Physics 49, 095302 (2016)10.1088/0022-3727/49/9/095302).

10. Y. Li, N. Sun, X. Li, J. Du, L. Chen, H. Gao, X. Hao, M. Cao, Multiple electrical response and enhanced energy storage induced by unusual coexistent-phase structure in relaxor ferroelectric ceramics. Acta Materialia 146, 202-210 (2018)10.1016/j.actamat.2017.12.048).

11. Q. Zhang, Y. Dan, J. Chen, Y. Lu, T. Yang, X. Yao, Y. He, Effects of composition and temperature on energy storage properties of $(\mathrm{Pb}, \mathrm{La})(\mathrm{Zr}, \mathrm{Sn}, \mathrm{Ti}) \mathrm{O}_{3}$ antiferroelectric ceramics. Ceramics International 43, 11428-11432 (2017)10.1016/j.ceramint.2017.06.005).

12. B. Peng, Z. Xie, Z. Yue, L. Li, Improvement of the recoverable energy storage density and efficiency by utilizing the linear dielectric response in ferroelectric capacitors. Applied Physics 
Letters 105, 052904 (2014)10.1063/1.4892454).

13. Z. Xie, Z. Yue, B. Peng, J. Zhang, C. Zhao, X. Zhang, G. Ruehl, L. Li, Large enhancement of the recoverable energy storage density and piezoelectric response in relaxor-ferroelectric capacitors by utilizing the seeding layers engineering. Applied Physics Letters 106, 202901 (2015)10.1063/1.4921404).

14. J. Rödel, K. G. Webber, R. Dittmer, W. Jo, M. Kimura, D. Damjanovic, Transferring lead-free piezoelectric ceramics into application. Journal of the European Ceramic Society 35, 16591681 (2015)10.1016/j.jeurceramsoc.2014.12.013).

15. C.-H. Hong, H.-P. Kim, B.-Y. Choi, H.-S. Han, J. S. Son, C. W. Ahn, W. Jo, Lead-free piezoceramics - Where to move on? Journal of Materiomics 2, 1-24 (2016)10.1016/j.jmat.2015.12.002).

16. Z. Liu, P. Ren, C. Long, X. Wang, Y. Wan, G. Zhao, Enhanced energy storage properties of $\mathrm{NaNbO}_{3}$ and $\mathrm{SrZrO}_{3}$ modified $\mathrm{Bi}_{0.5} \mathrm{Na}_{0.5} \mathrm{TiO}_{3}$ based ceramics. Journal of Alloys and Compounds 721, 538-544 (2017)10.1016/j.jallcom.2017.05.162).

17. Q. Chai, D. Yang, X. Zhao, X. Chao, Z. Yang, Lead-free (K,Na)NbO3-based ceramics with high optical transparency and large energy storage ability. Journal of the American Ceramic Society 101, 2321-2329 (2018)10.1111/jace.15392).

18. Z. Tang, J. Ge, H. Ni, B. Lu, X.-G. Tang, S.-G. Lu, M. Tang, J. Gao, High energy-storage density of lead-free $\mathrm{BiFeO}_{3}$ doped $\mathrm{Na}_{0.5} \mathrm{Bi}_{0.5} \mathrm{TiO}_{3}-\mathrm{BaTiO}_{3}$ thin film capacitor with good temperature stability. Journal of Alloys and Compounds 757, 169-176 (2018)10.1016/j.jallcom.2018.05.072).

19. H. Pan, Y. Zeng, Y. Shen, Y.-H. Lin, J. Ma, L. Li, C.-W. Nan, $\mathrm{BiFeO}_{3}-\mathrm{SrTiO}_{3}$ thin film as a 
new lead-free relaxor-ferroelectric capacitor with ultrahigh energy storage performance. Journal of Materials Chemistry A 5, 5920-5926 (2017)10.1039/c7ta00665a).

20. Z. Shen, X. Wang, B. Luo, L. Li, $\mathrm{BaTiO}_{3}-\mathrm{BiYbO}_{3}$ perovskite materials for energy storage applications. Journal of Materials Chemistry A 3, 18146-18153 (2015)10.1039/c5ta03614c).

21. B. Liu, X. Wang, R. Zhang, L. Li, Energy storage properties of ultra fine-grained $\mathrm{Ba}_{0.4} \mathrm{Sr}_{0.6}$ $\mathrm{TiO}_{3}$-based ceramics sintered at low temperature. Journal of Alloys and Compounds 691, 619623 (2017)10.1016/j.jallcom.2016.08.317).

22. L. Wu, X. Wang, H. Gong, Y. Hao, Z. Shen, L. Li, Core-satellite $\mathrm{BaTiO}_{3} @ \mathrm{SrTiO}_{3}$ assemblies for a local compositionally graded relaxor ferroelectric capacitor with enhanced energy storage density and high energy efficiency. Journal of Materials Chemistry C 3, 750-758 (2015)10.1039/c4tc02291b).

23. X. Zhao, Z. Zhou, R. Liang, F. Liu, X. Dong, High-energy storage performance in lead-free (1$x) \mathrm{BaTiO}_{3}-x \mathrm{Bi}\left(\mathrm{Zn}_{0.5} \mathrm{Ti}_{0.5}\right) \mathrm{O}_{3}$ relaxor ceramics for temperature stability applications. Ceramics International 43, 9060-9066 (2017)10.1016/j.ceramint.2017.04.051).

24. A. Zeb, S. J. Milne, S. Zhang, Stability of High-Temperature Dielectric Properties for $(1-x) \mathrm{Ba}_{0.8} \mathrm{Ca}_{0.2} \mathrm{TiO}_{3}-x \mathrm{Bi}\left(\mathrm{Mg}_{0.5} \mathrm{Ti}_{0.5}\right) \mathrm{O}_{3}$ Ceramics. Journal of the American Ceramic Society 96, 2887-2892 (2013)10.1111/jace.12412).

25. M. K. Shamim, S. Sharma, A. Singh, R. Rai, R. Rani, Study of the structural and electrical behavior of $\mathrm{Bi}(\mathrm{Mg}, \mathrm{Ti}) \mathrm{O}_{3}$ modified $(\mathrm{Ba}, \mathrm{Ca}) \mathrm{TiO}_{3}$ ceramics. Journal of Advanced Dielectrics $\mathbf{0 6}$, 1650035 (2016)10.1142/s2010135x16500351).

26. T. Rojac, A. Bencan, B. Malic, G. Tutuncu, J. L. Jones, J. E. Daniels, D. Damjanovic, D. J. Green, $\mathrm{BiFeO}_{3}$ Ceramics: Processing, Electrical, and Electromechanical Properties. Journal of 
the American Ceramic Society 97, 1993-2011 (2014)10.1111/jace.12982).

27. D. Ma, X. Chen, G. Huang, J. Chen, H. Zhou, L. Fang, Temperature stability, structural evolution and dielectric properties of $\mathrm{BaTiO}_{3}-\mathrm{Bi}\left(\mathrm{Mg}_{2 / 3} \mathrm{Ta}_{1 / 3}\right) \mathrm{O}_{3}$ perovskite ceramics. Ceramics International 41, 7157-7161 (2015)10.1016/j.ceramint.2015.02.036).

28. A. Dixit, S. B. Majumder, P. S. Dobal, R. S. Katiyar, A. S. Bhalla, Phase transition studies of sol-gel deposited barium zirconate titanate thin films. Thin Solid Films 447-448, 284-288 (2004)10.1016/s0040-6090(03)01065-4).

29. J. Pokorný, U. M. Pasha, L. Ben, O. P. Thakur, D. C. Sinclair, I. M. Reaney, Use of Raman spectroscopy to determine the site occupancy of dopants in $\mathrm{BaTiO}_{3}$. Journal of Applied Physics 109, $114110(2011) 10.1063 / 1.3592192)$.

30. A. A. Bokov, Z. G. Ye, Dielectric dispersion and critical behavior in relaxor ferroelectric $\mathrm{Pb}\left(\mathrm{Mg}_{1 / 3} \mathrm{Nb}_{2 / 3}\right) \mathrm{O}_{3}-\mathrm{PbTiO}_{3}$. Applied Physics Letters 77, 1888 (2000)10.1063/1.1310629).

31. D. Fu, H. Taniguchi, M. Itoh, S.-y. Koshihara, N. Yamamoto, S. Mori, Relaxor $\mathrm{Pb}\left(\mathrm{Mg}_{1 / 3} \mathrm{Nb}_{2 / 3}\right) \mathrm{O}_{3}$ : A Ferroelectric with Multiple Inhomogeneities. Physical review letters 103, (2009)10.1103/PhysRevLett.103.207601).

32. A. A. Bokov, Y. H. Bing, W. Chen, Z. G. Ye, S. A. Bogatina, I. P. Raevski, S. I. Raevskaya, E. V. Sahkar, Empirical scaling of the dielectric permittivity peak in relaxor ferroelectrics. Physical Review B 68, (2003)10.1103/PhysRevB.68.052102).

33. S. Ke, H. Fan, H. Huang, H. L. W. Chan, Lorentz-type relationship of the temperature dependent dielectric permittivity in ferroelectrics with diffuse phase transition. Applied Physics Letters 93, 112906 (2008)10.1063/1.2987733).

34. S. Ma, X. Cheng, J. Hao, W. Li, R. Chu, Z. Xu, Dielectric and ferroelectric properties of Ta- 
modified $\mathrm{Bi}_{3.25} \mathrm{La}_{0.75} \mathrm{Ti}_{3} \mathrm{O}_{12} \quad$ ceramics. Ceramics International 43, 13193-13198 (2017)10.1016/j.ceramint.2017.07.013).

35. X. Hao, J. Zhai, L. B. Kong, Z. Xu, A comprehensive review on the progress of lead zirconatebased antiferroelectric materials. Progress in Materials Science 63, 1-57 (2014)10.1016/j.pmatsci.2014.01.002).

36. A. Chauhan, S. Patel, R. Vaish, Mechanical confinement for improved energy storage density in BNT-BT-KNN lead-free ceramic capacitors. AIP Advances 4, 087106 (2014)10.1063/1.4892608).

37. D. Zheng, R. Zuo, D. Zhang, Y. Li, X. Tan, Novel BiFeO ${ }_{3}-\mathrm{BaTiO}_{3}-\mathrm{Ba}\left(\mathrm{Mg}_{1 / 3} \mathrm{Nb}_{2 / 3}\right) \mathrm{O}_{3}$ LeadFree Relaxor Ferroelectric Ceramics for Energy-Storage Capacitors. Journal of the American Ceramic Society 98, 2692-2695 (2015)10.1111/jace.13737).

38. Q. Xu, H. Liu, L. Zhang, J. Xie, H. Hao, M. Cao, Z. Yao, M. T. Lanagan, Structure and electrical properties of lead-free $\mathrm{Bi}_{0.5} \mathrm{Na}_{0.5} \mathrm{TiO}_{3}$-based ceramics for energy-storage applications. $R S C$ Advances 6, 59280-59291 (2016)10.1039/c6ra11744a). 


\section{Figure Captions:}

Figure 1. a) XRD patterns of BFO-doped BCT-BMT-based ceramics. b) enlarged (110), (111) and (002) profiles of XRD patterns, respectively. c) Raman spectra of BFO-doped BCT-BMT-based ceramics at room temperature. d) Variations of height, center and width of $\mathrm{A}_{1}\left(\mathrm{TO}_{3}\right) / \mathrm{E}(\mathrm{TO})$ mode.

Figure 2. Surface SEM images of BFO-doped BCT-BMT-based ceramics after thermal etched at 2 K magnification. a) $x=0$, b) $x=0.01$, c) $x=0.02$, d) $x=0.03$, e) $x=0.04$, f) $x=0.05$, g) $x=0.06$ and h) $x=0.07$. Insets of Fig. 2a) - 2h): the statistic distributions of the grain sizes in ceramics.

Figure 3. P-E loops of BFO-doped BCT-BMT-based as-prepared and corresponding aged ceramics. a) and b) $x=0.05$; c) and d) $x=0.06$; e) and f) $x=0.07$. The left upper corners insets of c) and e): complex impedance plots of as-prepared and corresponding aged ceramics at room temperature.

The left upper corners insets of d): The left upper corners insets of d): schematic diagram of aged samples at $x=0.06$ and 0.07 heated at $300{ }^{\circ} \mathrm{C}$ for $30 \mathrm{~min}$. The right lower corner insets of a), b), c), d), e) and f): $I-E$ loops.

Figure 4. $W_{\text {energy, }}, W_{\text {loss, }} \eta$ and $Q$ of BFO-doped BCT-BMT-based as-prepared and corresponding aged ceramics at selected electric fields. a) $W_{\text {energy, }}$ b) $W_{\text {loss, }}$ c) $\eta$ and $Q$.

Figure 5. P-E loops of BFO-doped BCT-BMT-based ceramics at 303 - $453 \mathrm{~K}$ and $1 \mathrm{~Hz}$. a) $x=0$, b) $x=0.01$, c) $x=0.02$, d) $x=0.03$, e) $x=0.04$, f) $x=0.05$. The left upper corners insets of a), b), c), d), e) and f): $\eta(T)$ and $Q(T)$. The right lower corners insets of a), b), c), d), e) and f): $W_{\text {energy }}(T)$ and $W_{\text {loss }}(T)$.

Table 1. Lorenz-type fitting results of the dielectric peaks of BFO-doped BCT-BMT-based ceramics including the as-prepared and aged ceramics at $1 \mathrm{MHz}$. 
a)

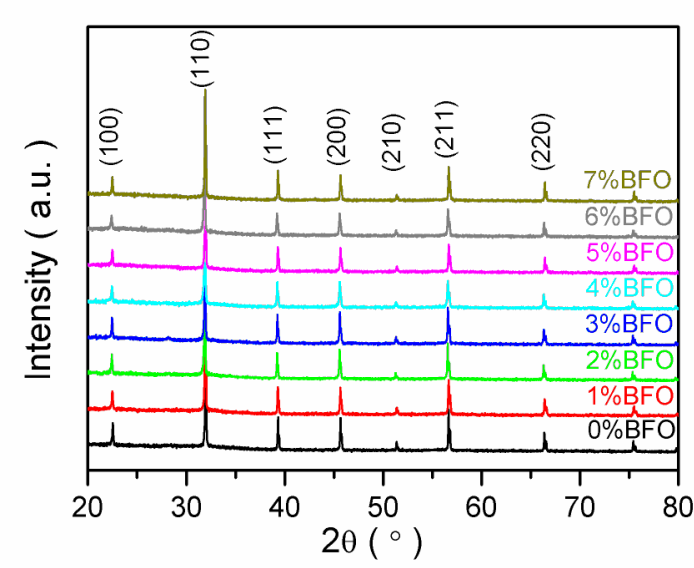

c)

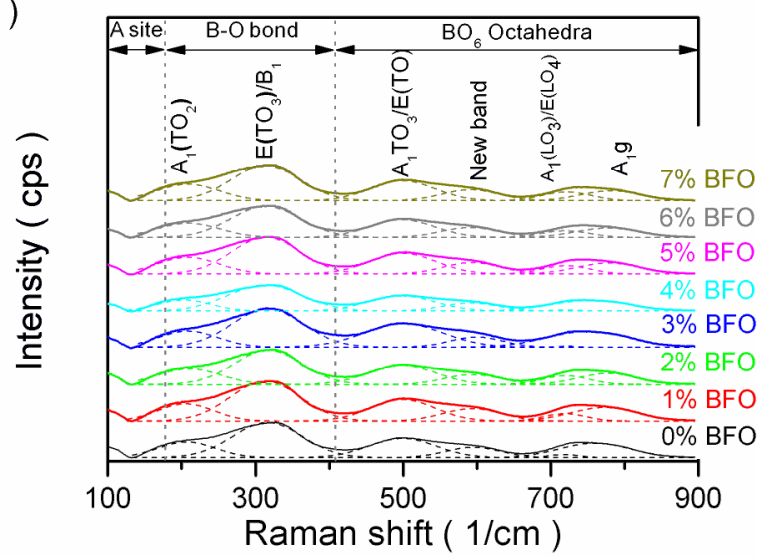

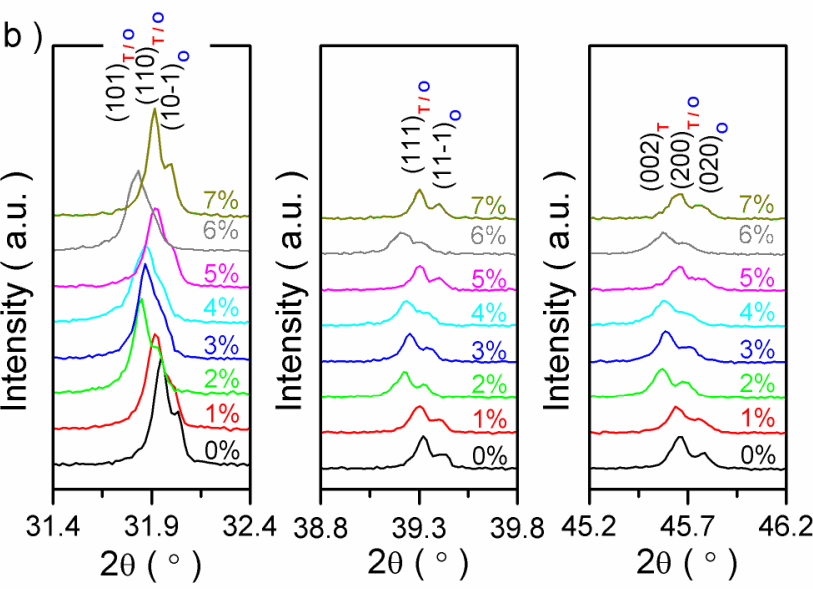

d)

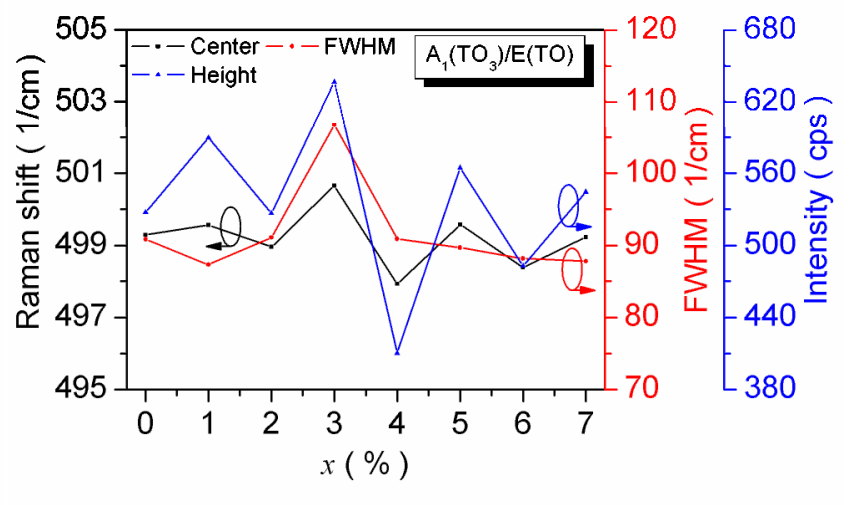

Figure 1 


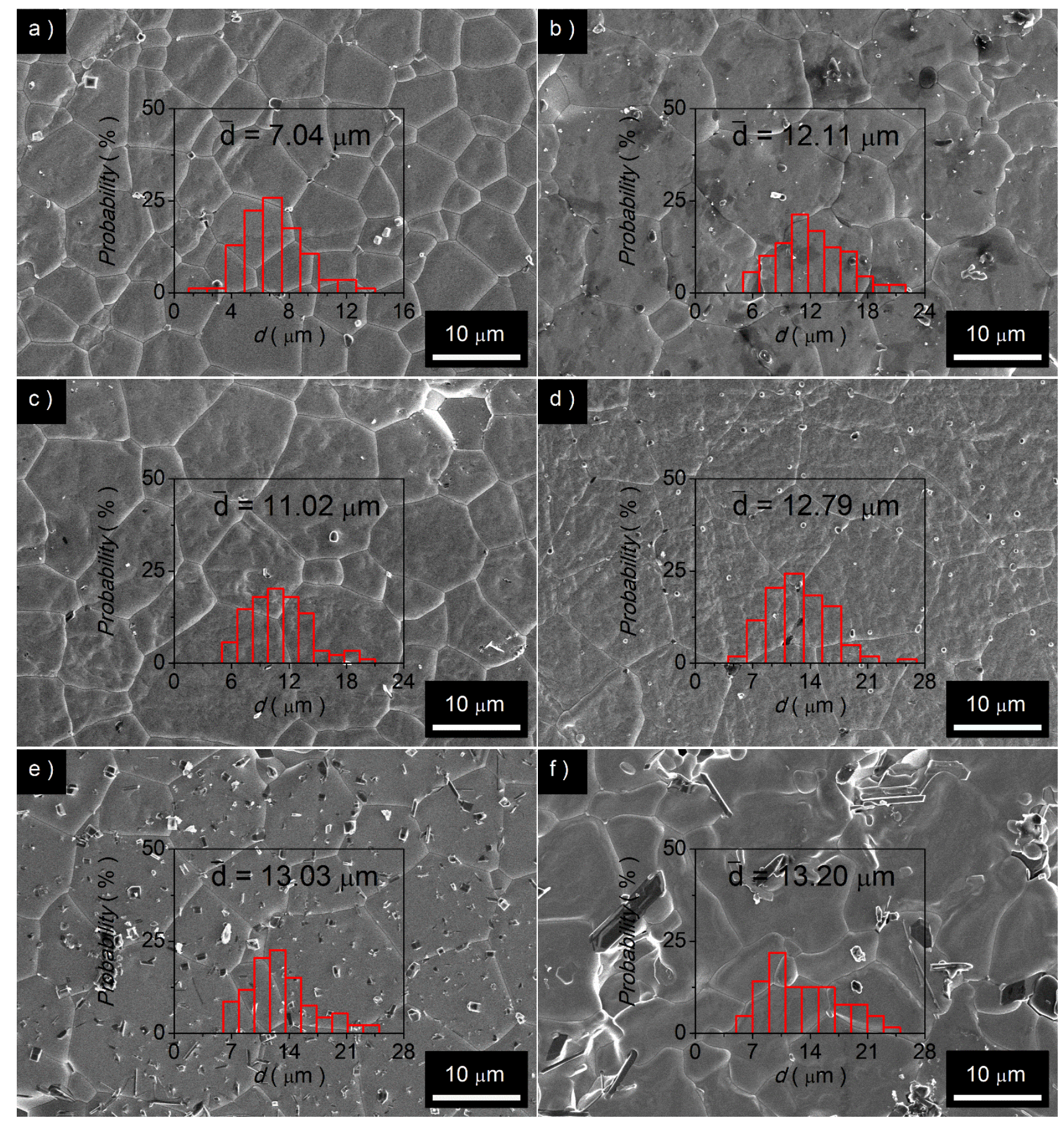




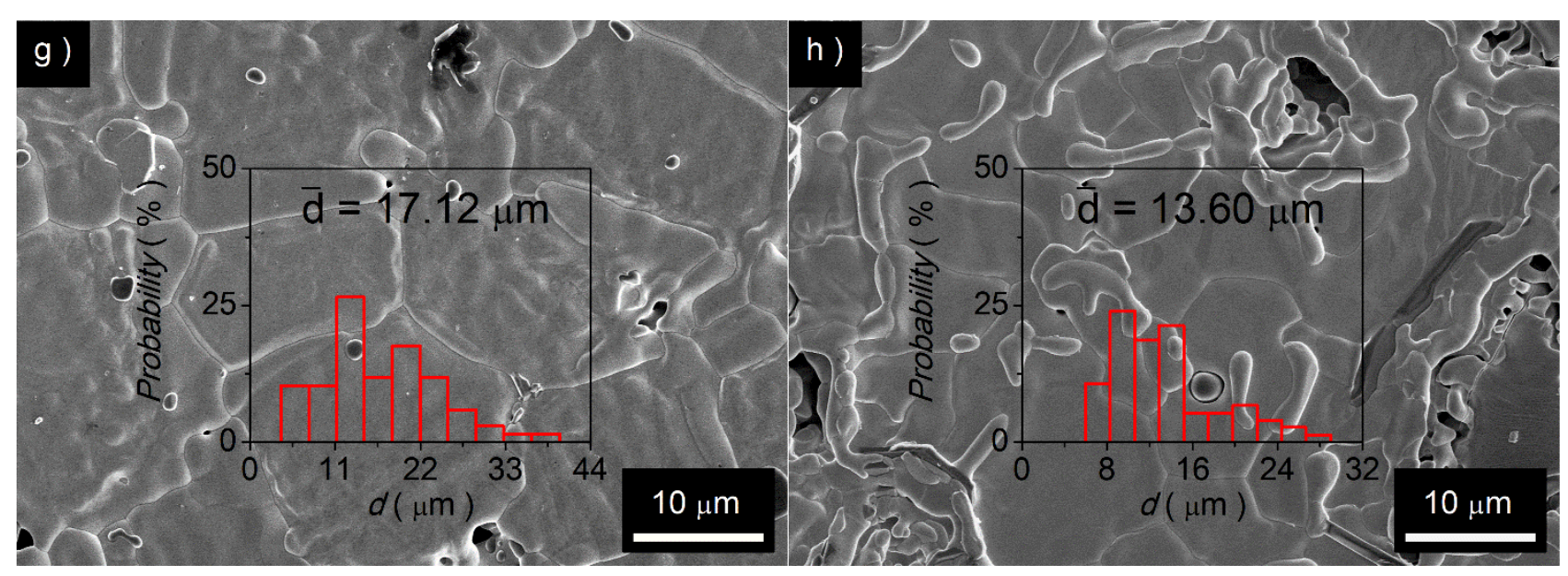

Figure 2 

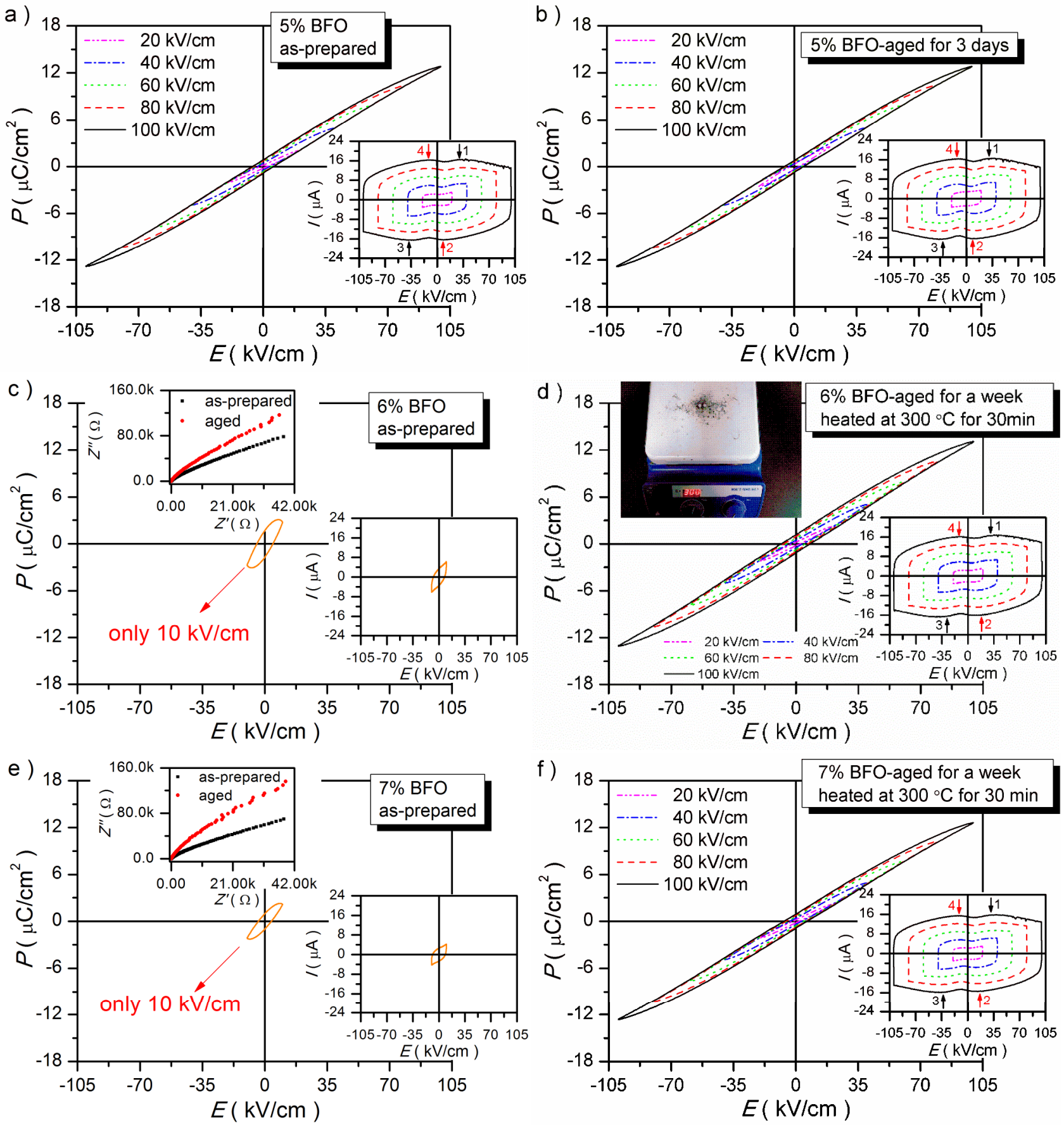

Figure 3 


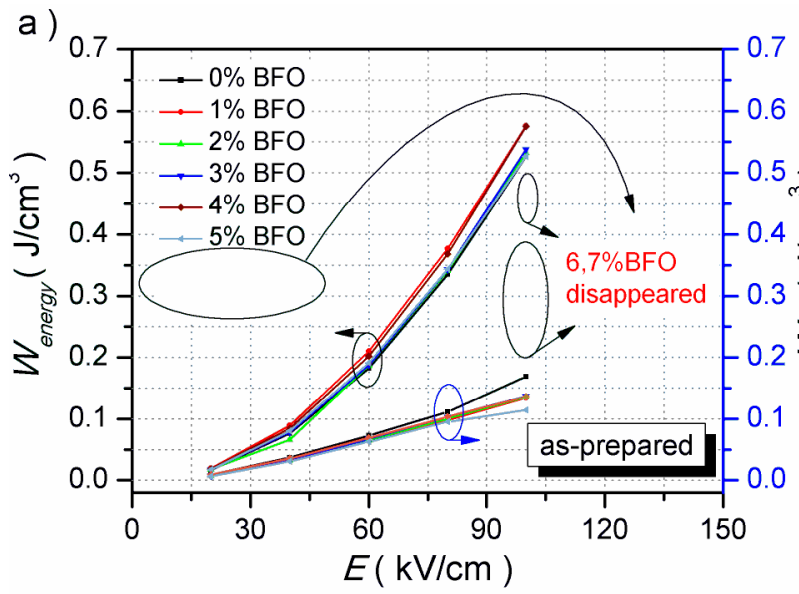

c)
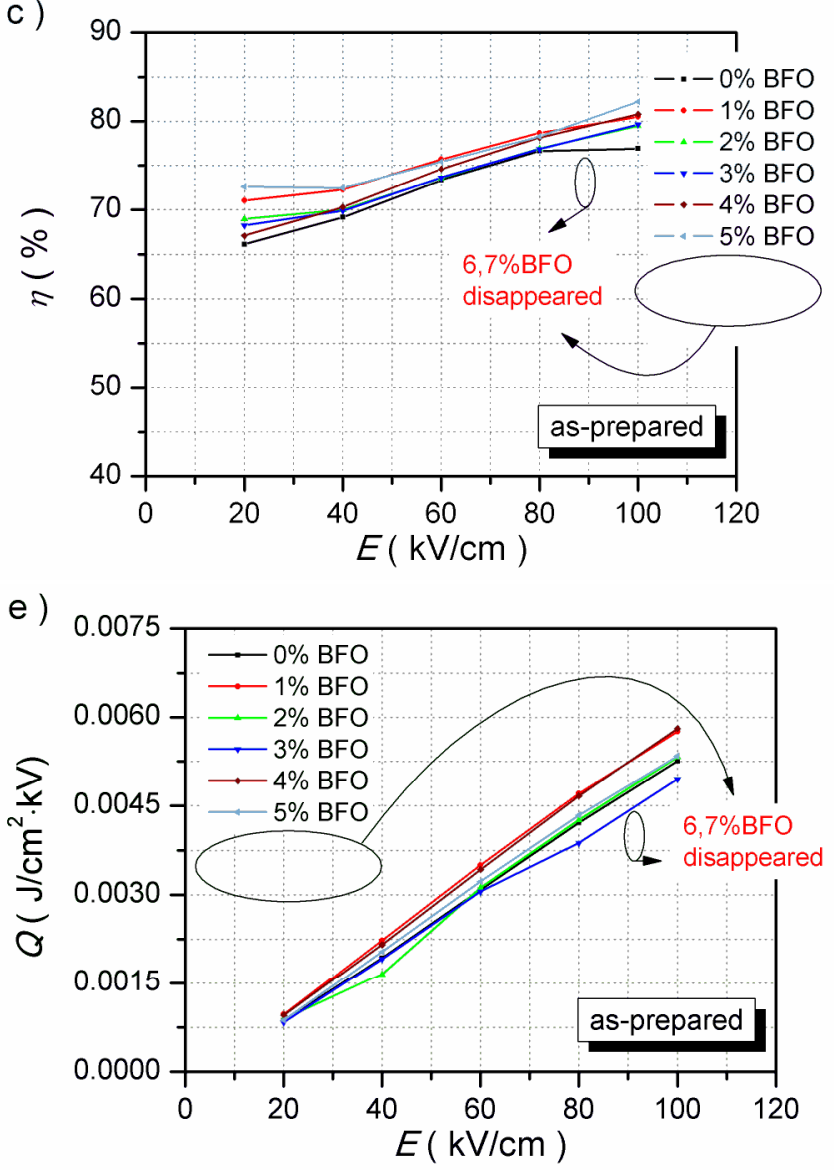

b)

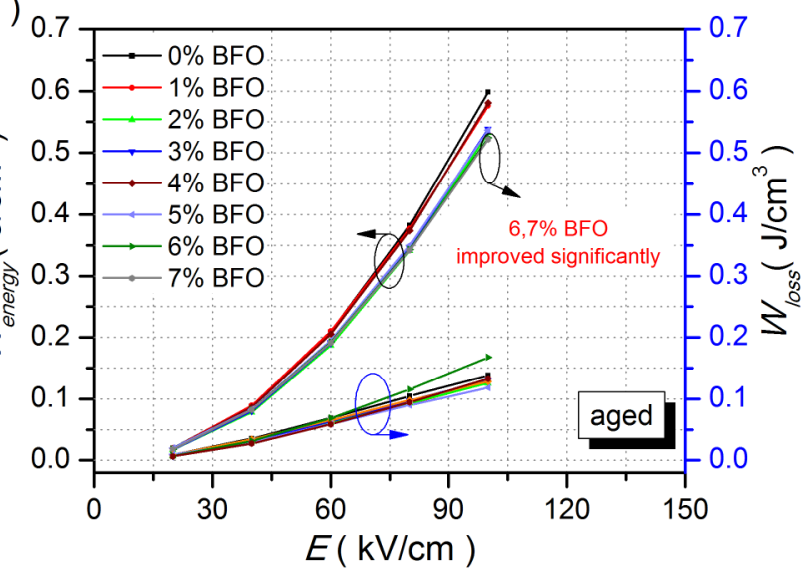

d)
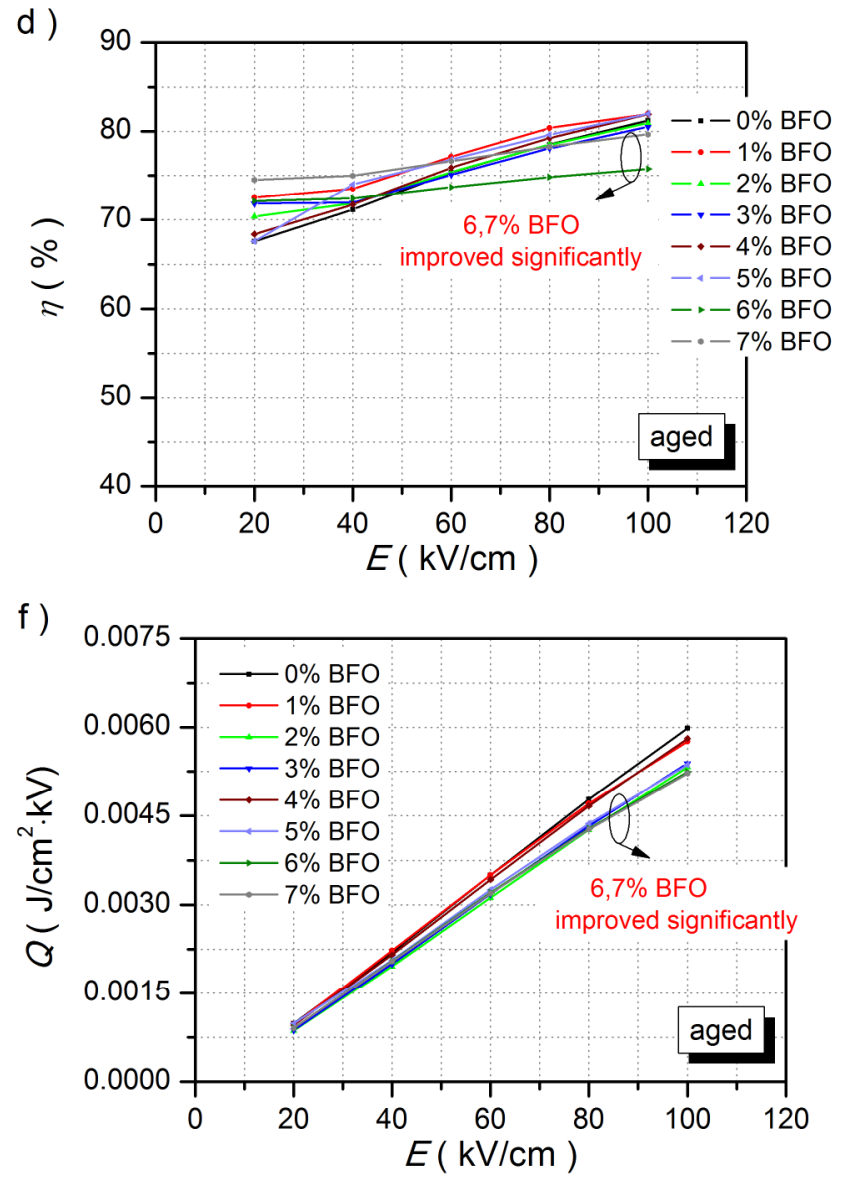

Figure 4 

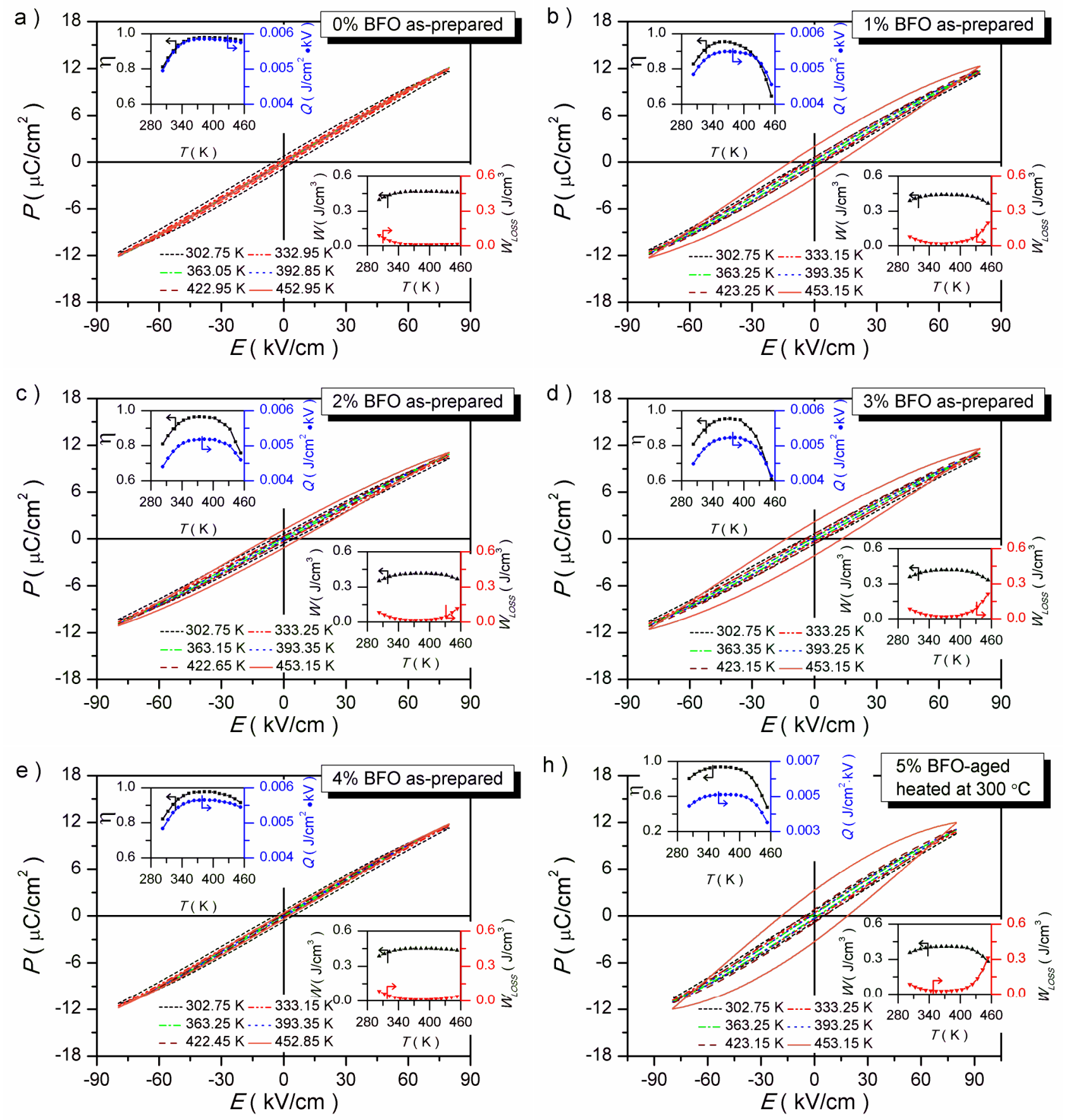

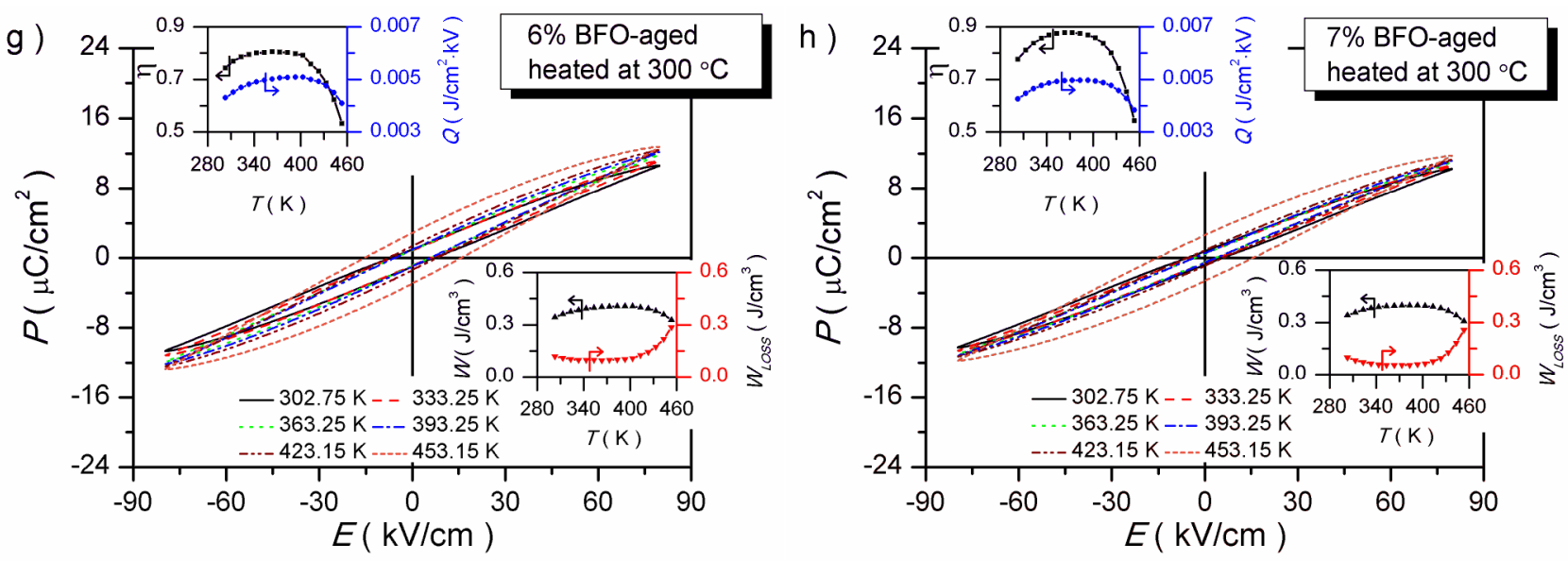

Figure 5 
Table 1

\begin{tabular}{lcccccc}
\hline \multirow{2}{*}{ sample } & \multicolumn{2}{c}{$T_{A}(K)$} & \multicolumn{2}{c}{$\varepsilon_{A}$} & \multicolumn{2}{c}{$\delta_{A}$} \\
\cline { 2 - 7 } & as-prepared & aged & as-prepared & aged & as-prepared & aged \\
\hline 0 & 513.20 & 509.67 & 1407.25 & 2271.80 & 134.23 & 146.99 \\
0.01 & 512.58 & 516.20 & 1420.89 & 1934.92 & 132.99 & 159.22 \\
0.02 & 513.07 & 514.97 & 2061.50 & 2348.84 & 156.80 & 169.62 \\
0.03 & 517.74 & 527.66 & 1228.40 & 1182.53 & 130.87 & 139.43 \\
0.04 & 512.39 & 515.09 & 907.33 & 1256.37 & 106.58 & 125.92 \\
0.05 & 514.94 & 518.97 & 1549.21 & 1187.92 & 142.90 & 130.14 \\
0.06 & 515.11 & 520.30 & 1515.97 & 1687.89 & 143.13 & 159.66 \\
0.07 & 520.17 & 527.30 & 887.04 & 1408.41 & 121.14 & 152.54 \\
\hline
\end{tabular}




\section{Supplementary Materials for}

\section{Enhanced energy storage performance of $\mathrm{BiFeO}_{3}$-doped BCT-BMT lead-free}

\section{relaxor ferroelectric ceramics in a broad temperature range}

Mengxing $\mathrm{Xu}^{1,3}$, Biaolin Peng ${ }^{1,3 *}$, Jinian $\mathrm{Zhu}^{2}$, Laijun Liu ${ }^{1 *}$, Wenhong Sun ${ }^{3 *}$, Glenn J.T. Leighton ${ }^{1}$, Christopher Shaw ${ }^{1}$, Qi Zhang ${ }^{1}$

${ }^{1}$ Department of Manufacturing and Materials, Cranfield University, Cranfield, Bedfordshire, MK43

0AL, United Kingdom

${ }^{2}$ State Key Laboratory of Nickel and Cobalt Resources Comprehensive Utilization, Jinchang, Gansu, 737100, China

${ }^{3}$ Center on Nanoenergy Research, School of Physical Science \& Technology, Guangxi University, Nanning 530004, China

*Correspondence to: pengbL8@126.com, 1j1iu2@163.com,20180001@gxu.edu.cn

This PDF file includes:

Figure S1 to S7 


\section{Figure Captions:}

Figure S1. Variations of height, center and width at different Raman shift, respectively. a) $\mathrm{A}_{1}\left(\mathrm{TO}_{2}\right)$ and $\mathrm{E}\left(\mathrm{TO}_{3}\right) / \mathrm{B}_{1}$ mode, $\left.\mathrm{b}\right)$ New band and $\mathrm{A}_{1}\left(\mathrm{LO}_{3}\right) / \mathrm{E}\left(\mathrm{LO}_{4}\right)$ mode, c) $\mathrm{A}_{1} g$ mode.

Figure S2. Surface SEM images of BFO-doped BCT-BMT-based ceramics after thermal etched at 1 K magnification. a) $x=0$, b) $x=0.1$, c) $x=0.02$, d) $x=0.03$, e) $x=0.04$, f) $x=0.05$, g) $x=0.06$ and h) $x=0.07$.

Figure S3. $\varepsilon(T)$ and $\tan \delta(T)$ of BFO-doped BCT-BMT-based as-prepared and corresponding aged ceramics. a) and b) $x=0$; c) and d) $x=0.01$; e) and f) $x=0.02$; g) and h) $x=0.03$; i) and j) $x=$ 0.04 ; $)$ and 1) $x=0.05 ; \mathrm{m})$ and n) $x=0.06$; o) and p) $x=0.07$.

Figure S4. P-E loops of BFO-doped BCT-BMT-based as-prepared and corresponding aged ceramics. a) and b) $x=0$; c) and d) $x=0.01$; e) and f) $x=0.02$; g) and h) $x=0.03$; i) and j) $x=0.04$. Insets: $I-E$ loops.

Figure S5. P-E loops of BFO-doped BCT-BMT-based ceramics at different aging times. a), c), e) and g) $x=0.06$; b), d), f) and h) $x=0.07$. The right lower corners insets: $I-E$ loops.

Figure S6. Frequency dependences of ac conductivity $\sigma_{\mathrm{ac}}$ for BFO-doped BCT-BMT-based asprepared and corresponding aged ceramics at selected temperatures. a) and b) $x=0$; c) and d) $x$ $=0.01$; e) and f) $x=0.02 ; \mathrm{g}$ ) and $\mathrm{h}) x=0.03 ; \mathrm{i})$ and $\mathrm{j}) x=0.04 ; \mathrm{k}$ ) and $\mathrm{l}) x=0.05 ; \mathrm{m})$ and $\mathrm{n}) x=0.06$; o) and p) $x=0.07$

Figure S7. $\varepsilon(f)$ and $\tan \delta(f)$ of BFO-doped BCT-BMT-based ceramics at room temperature. a) and b) as-prepared; c) and d) aged; e) and f) oxidized. 

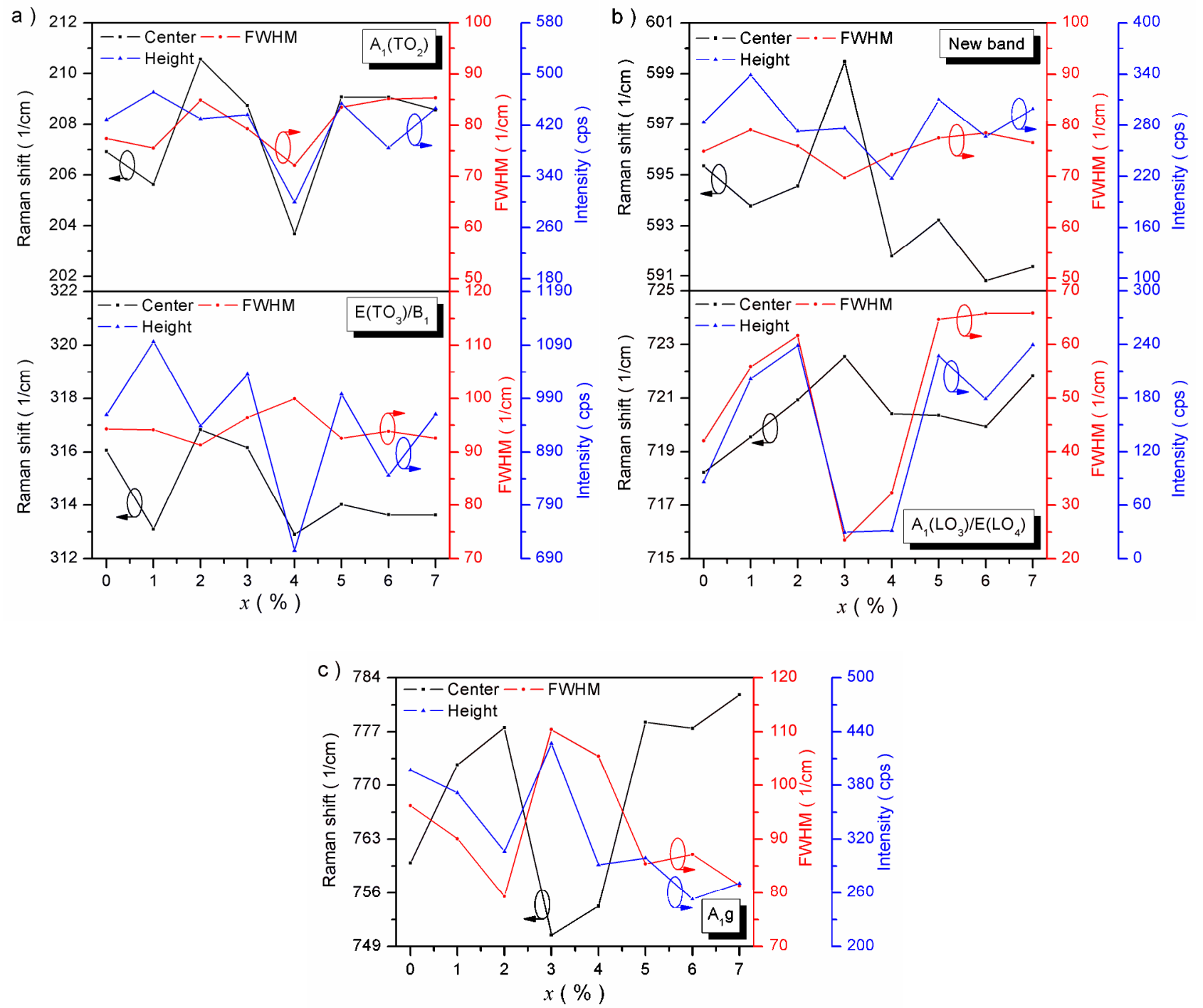

Figure S1 


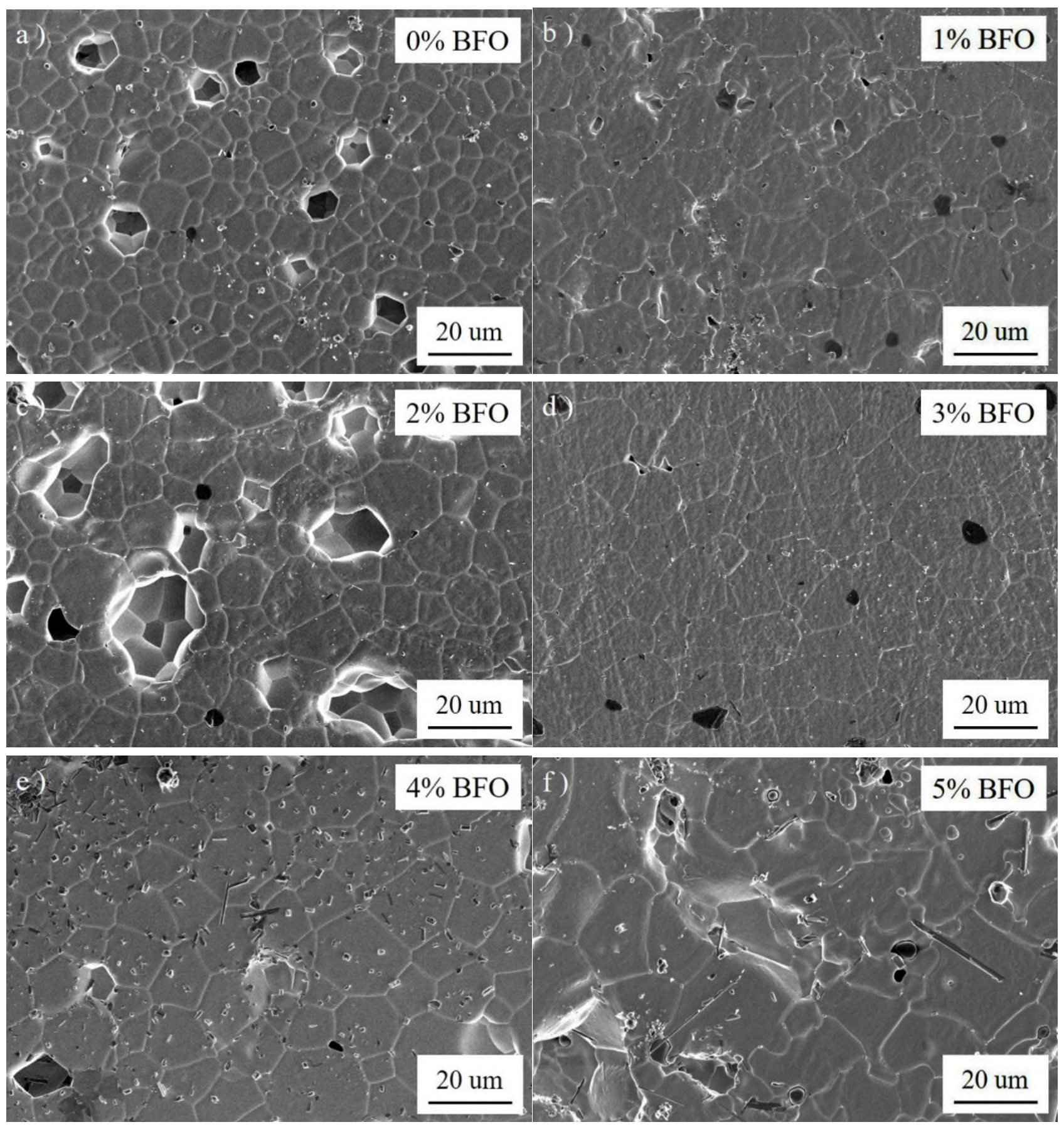




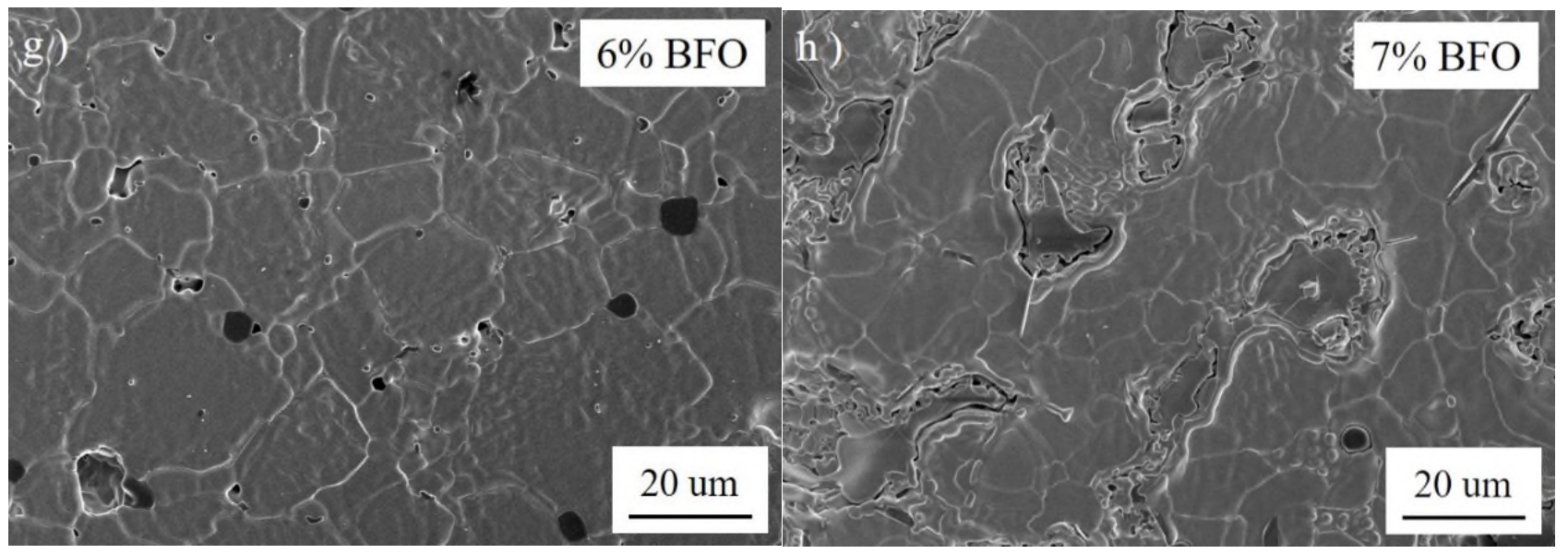

Figure S2 

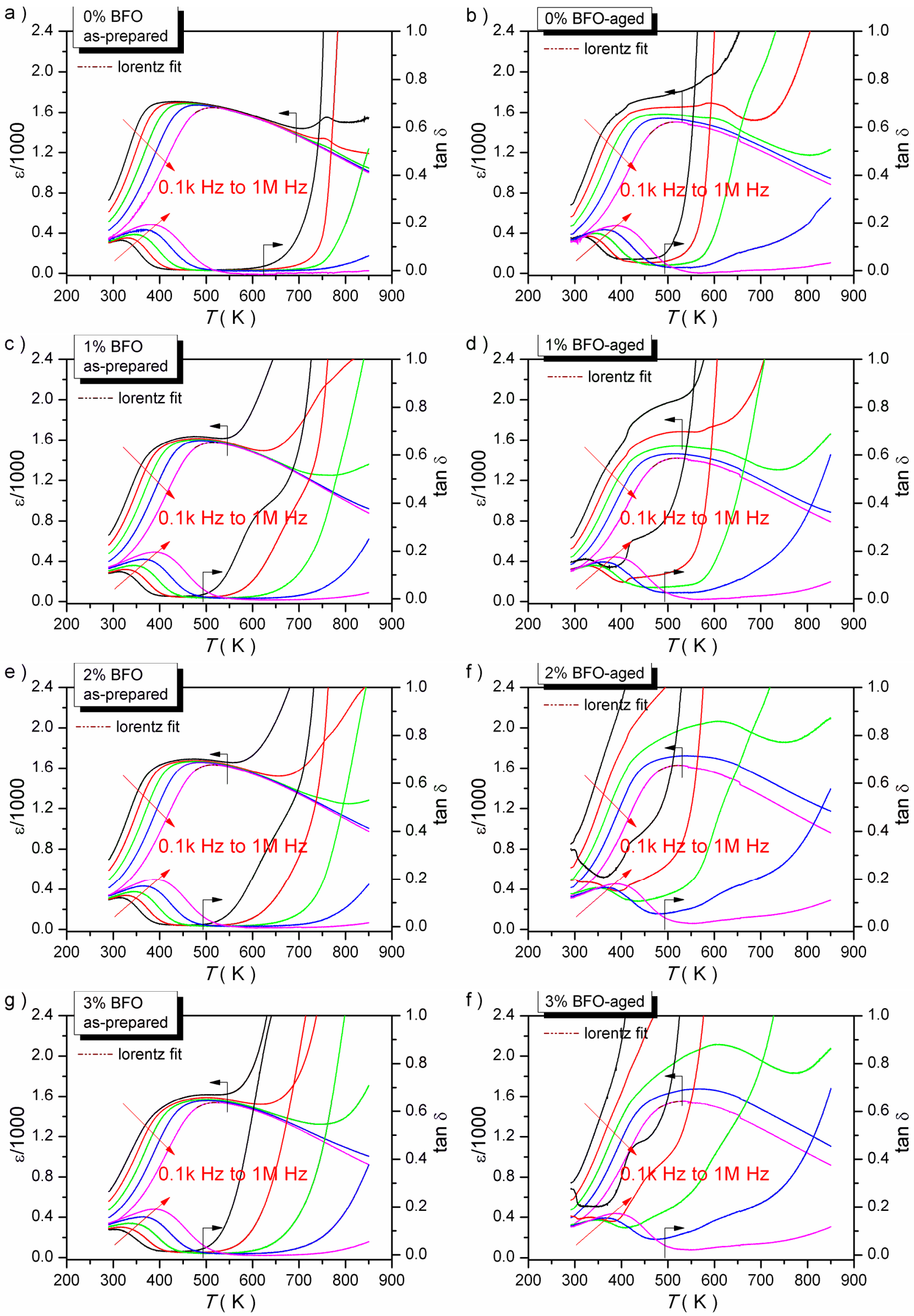

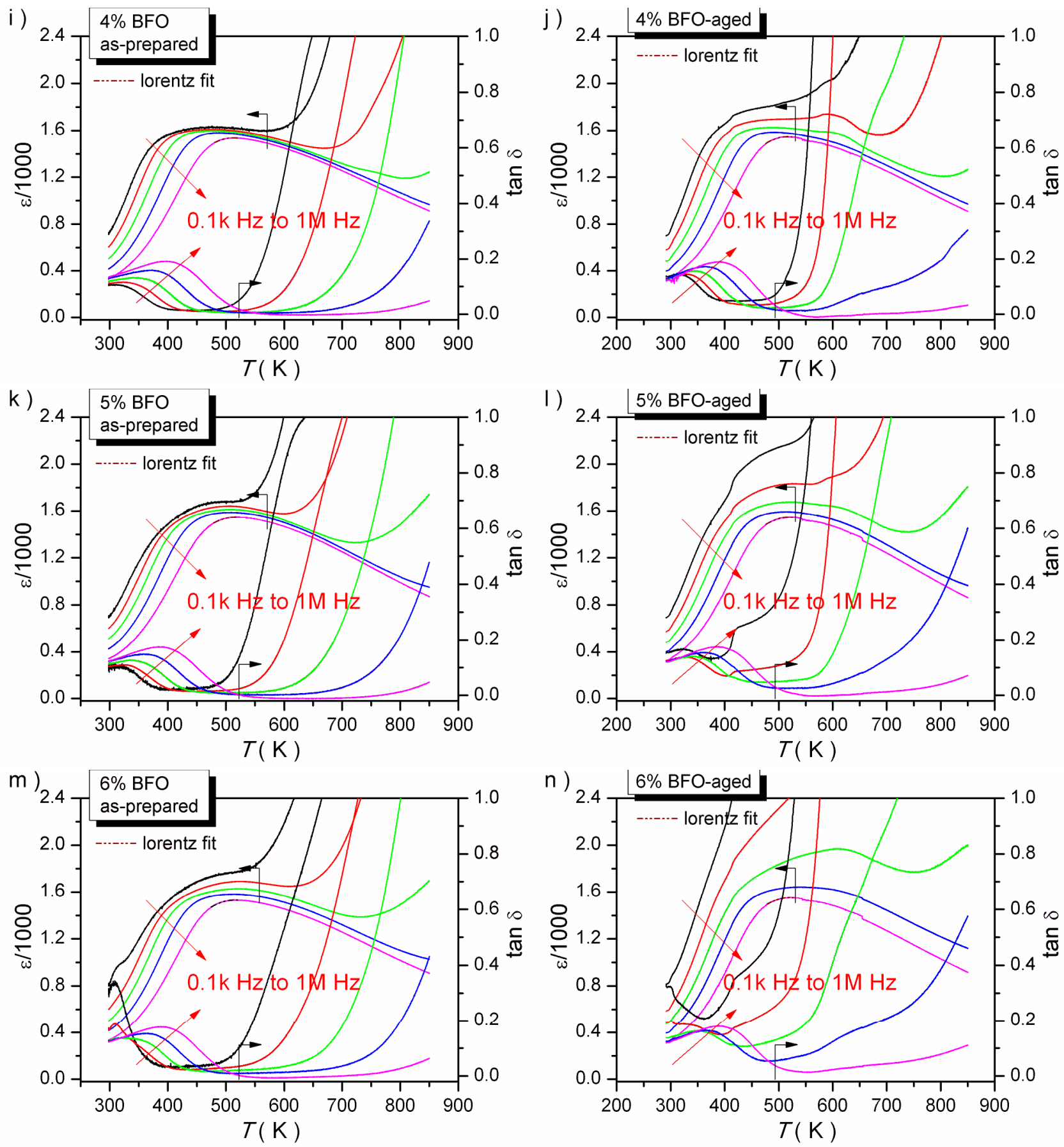

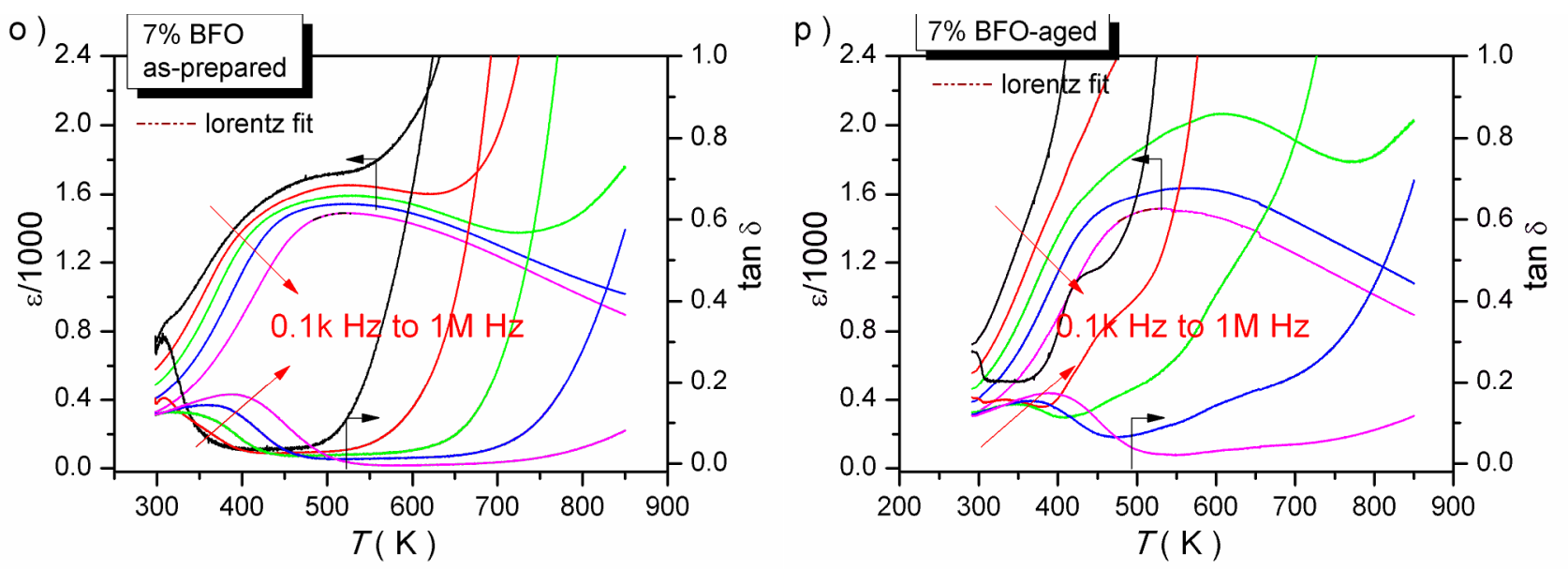

Figure S3 

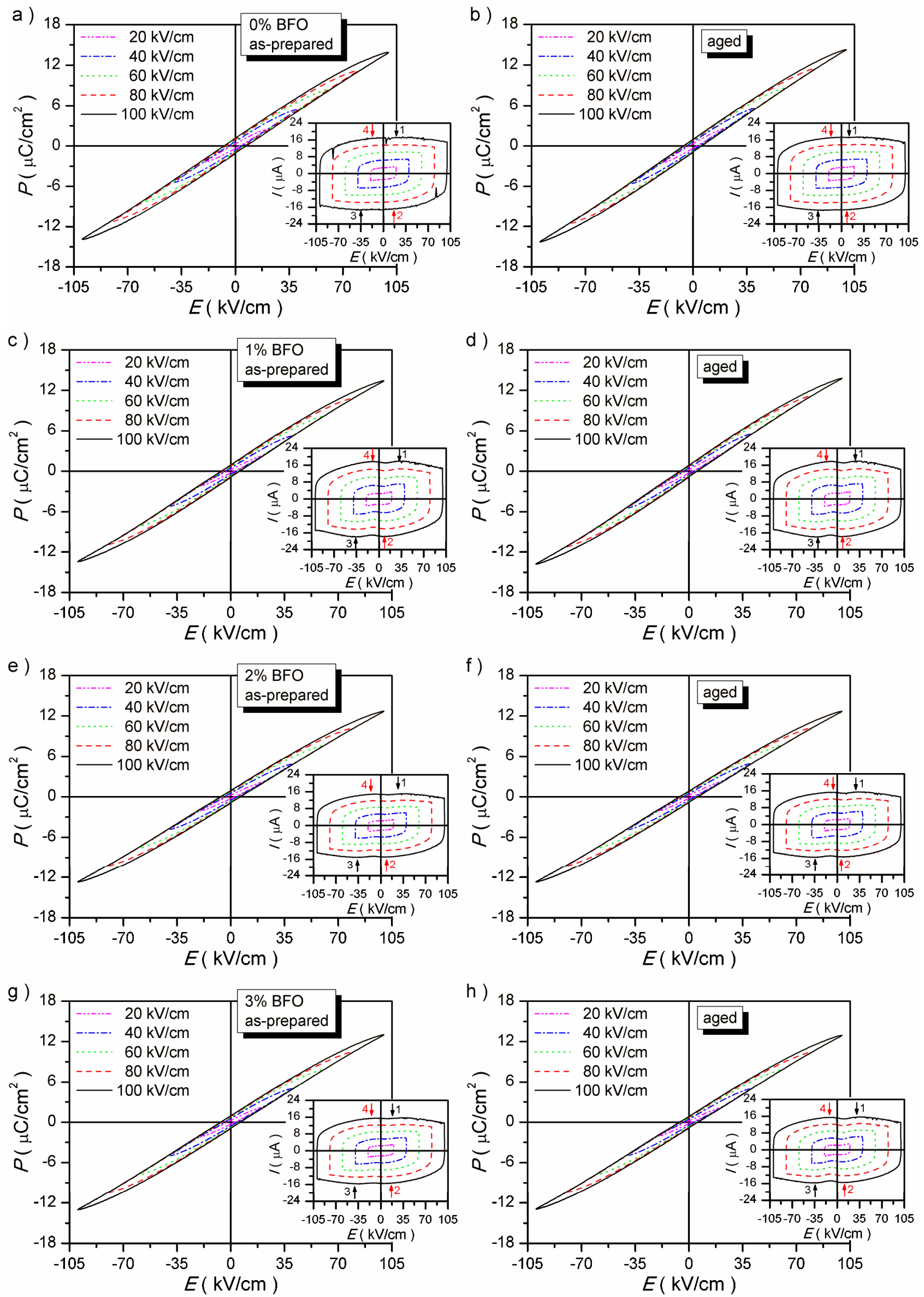

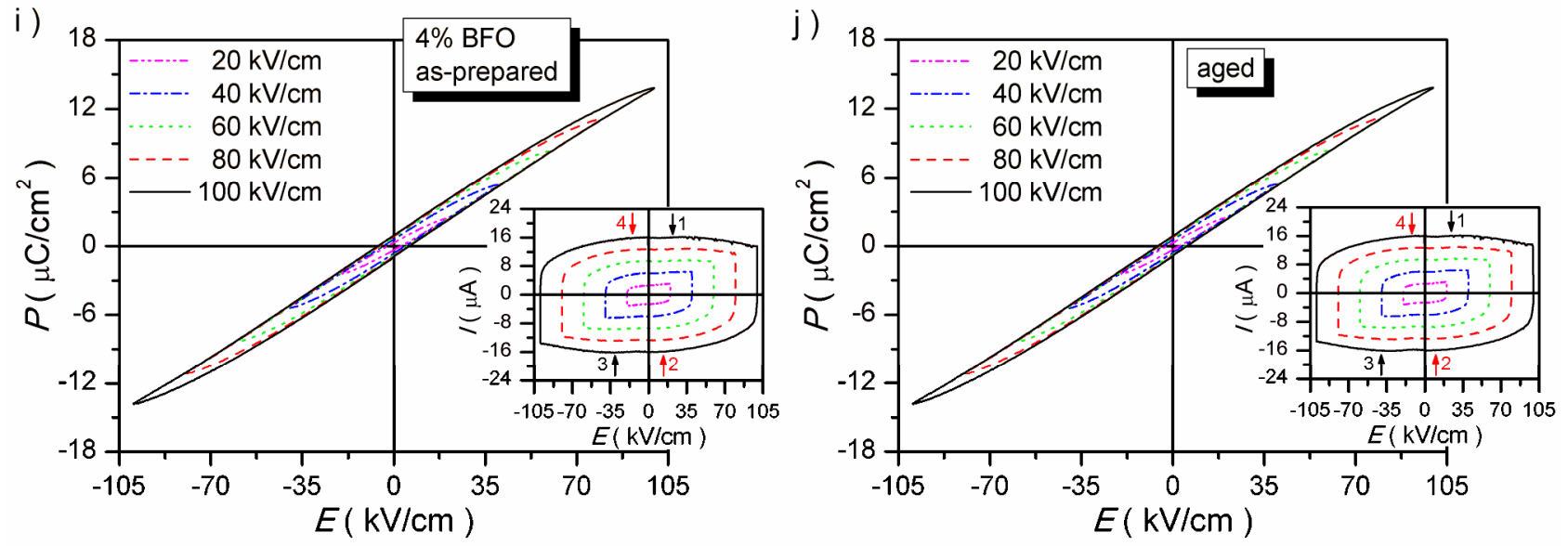

Figure S4 

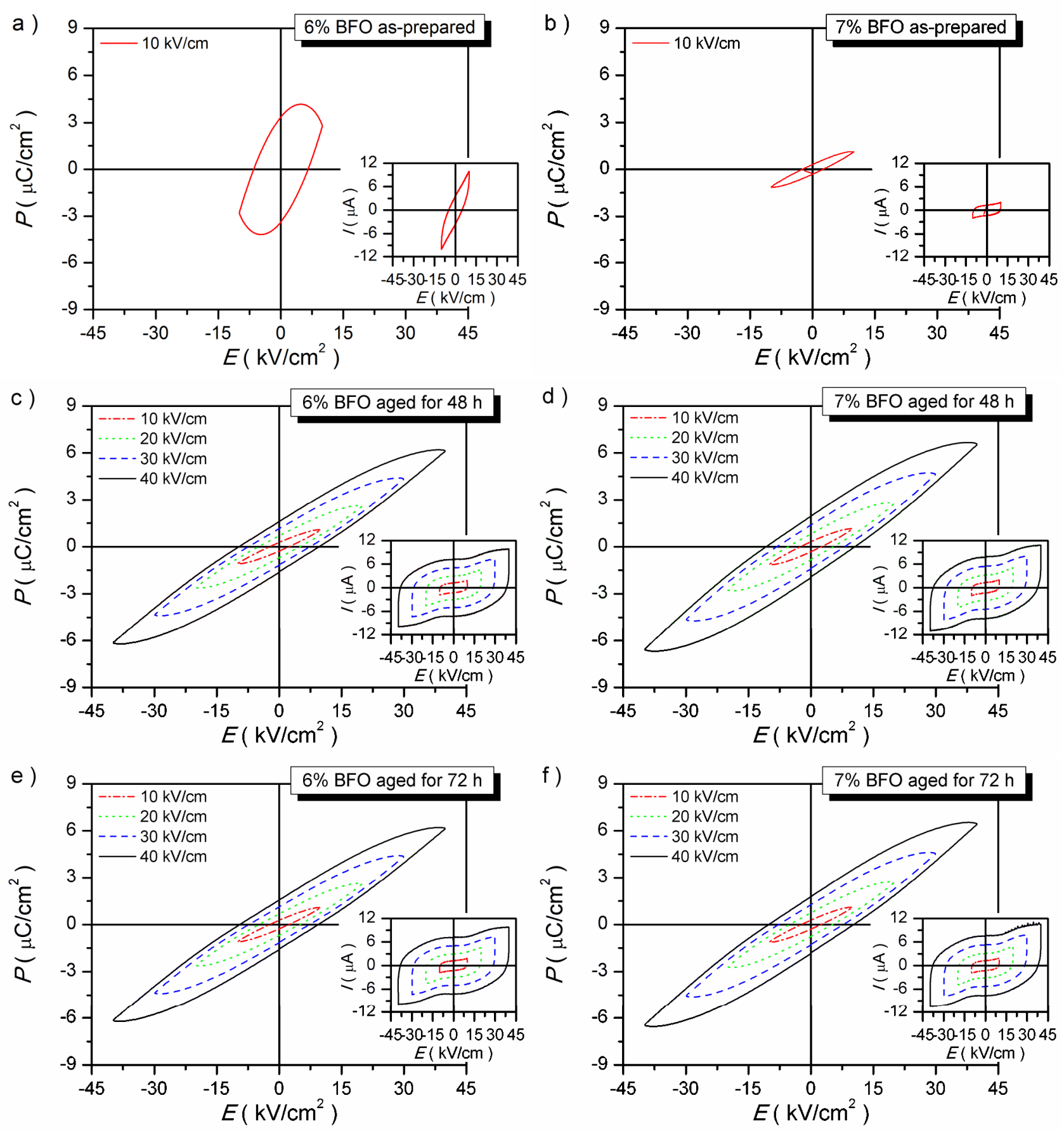

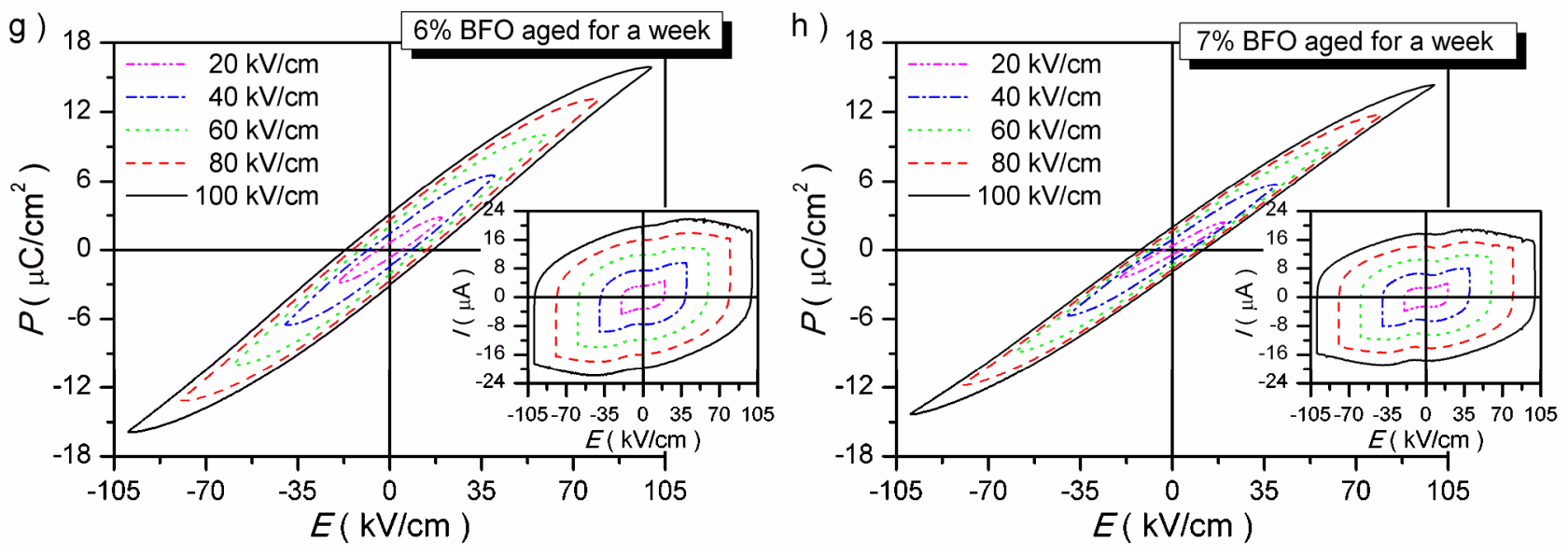

Figure S5 

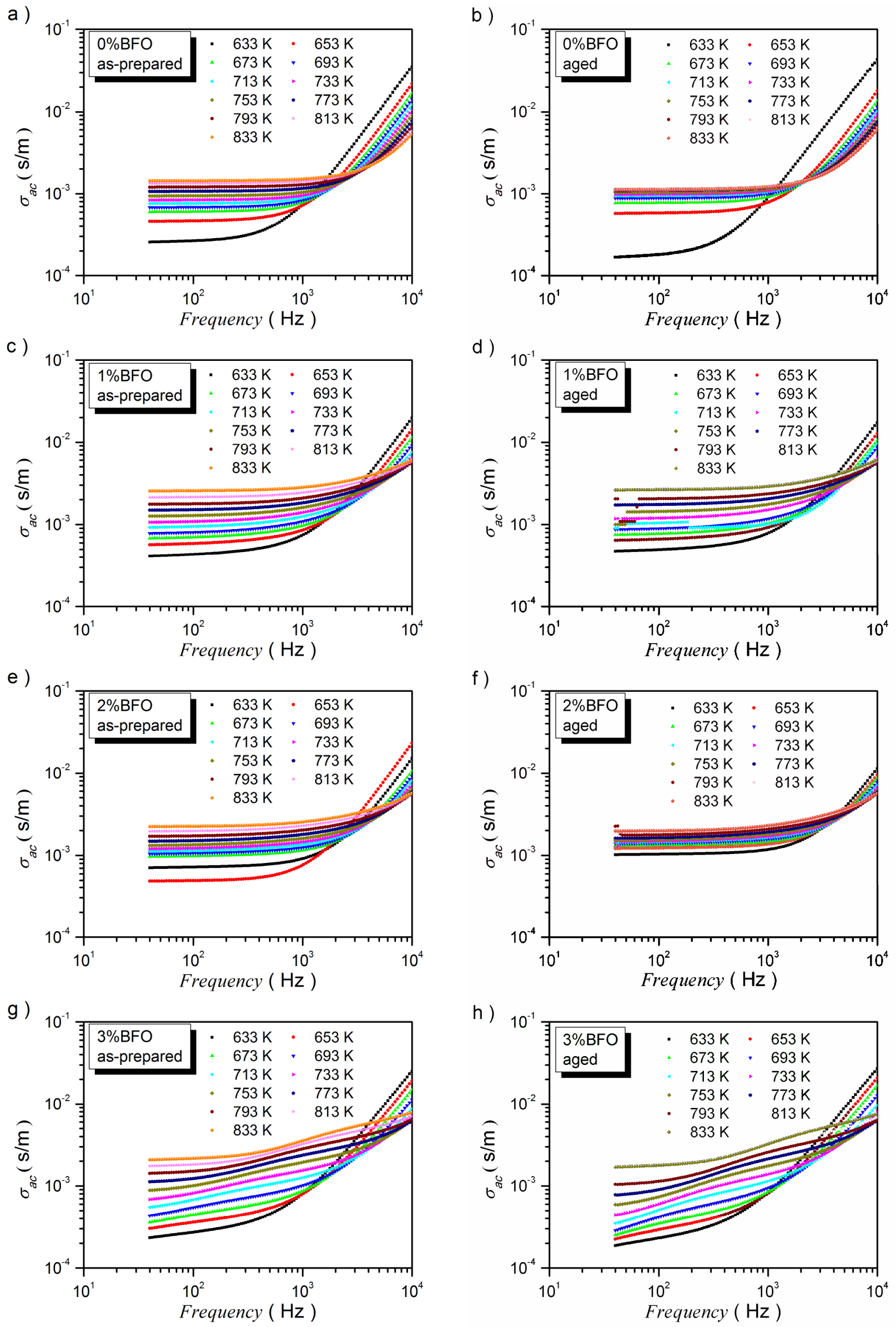

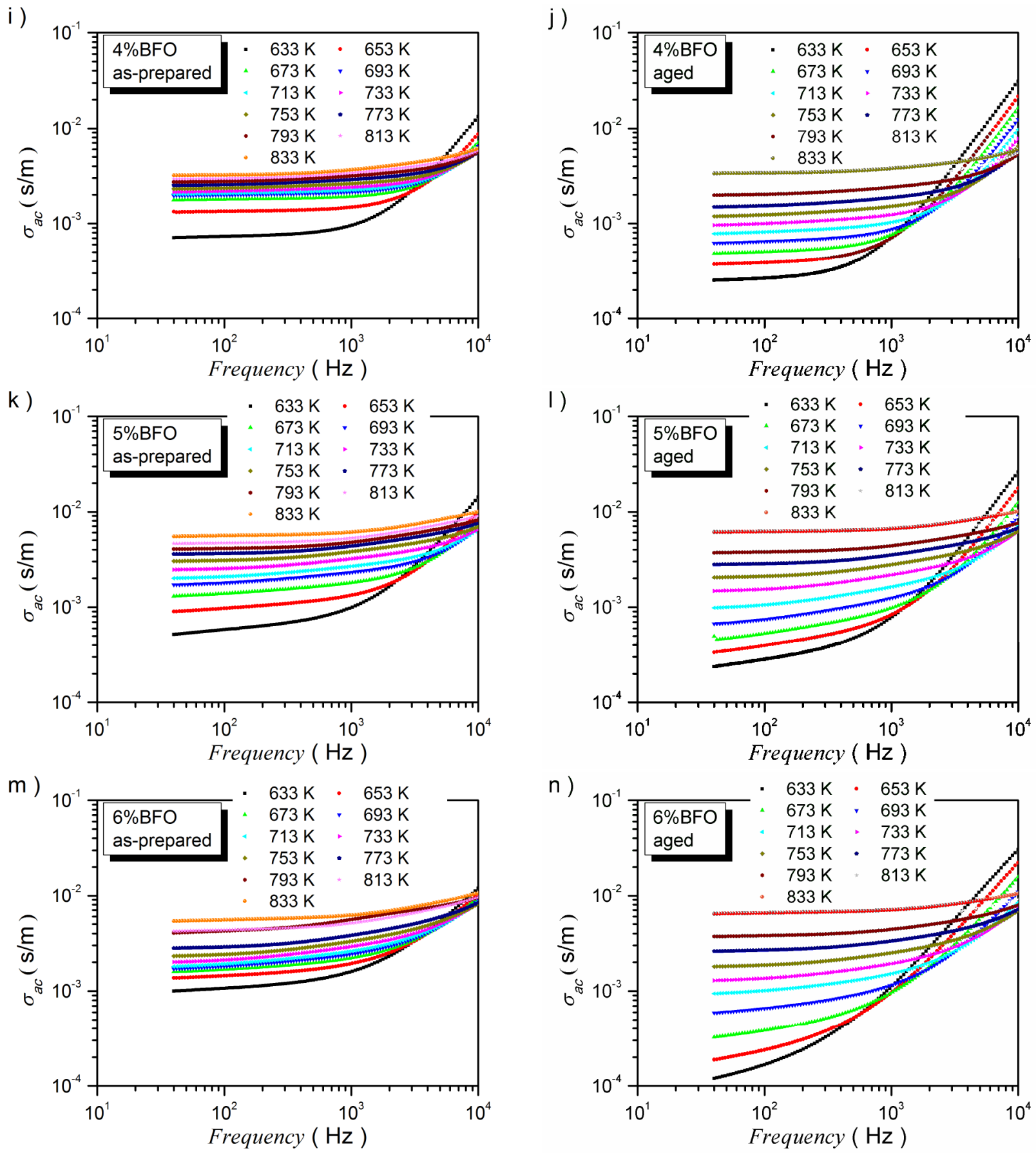

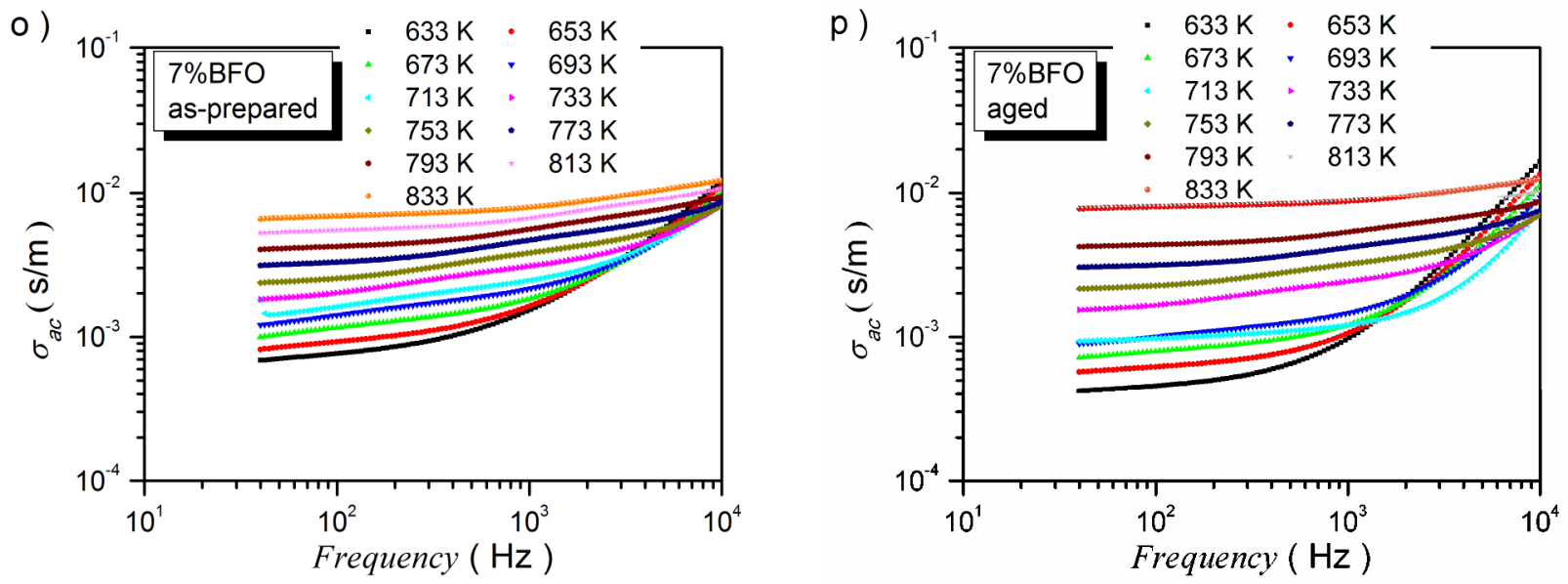

Figure S6 

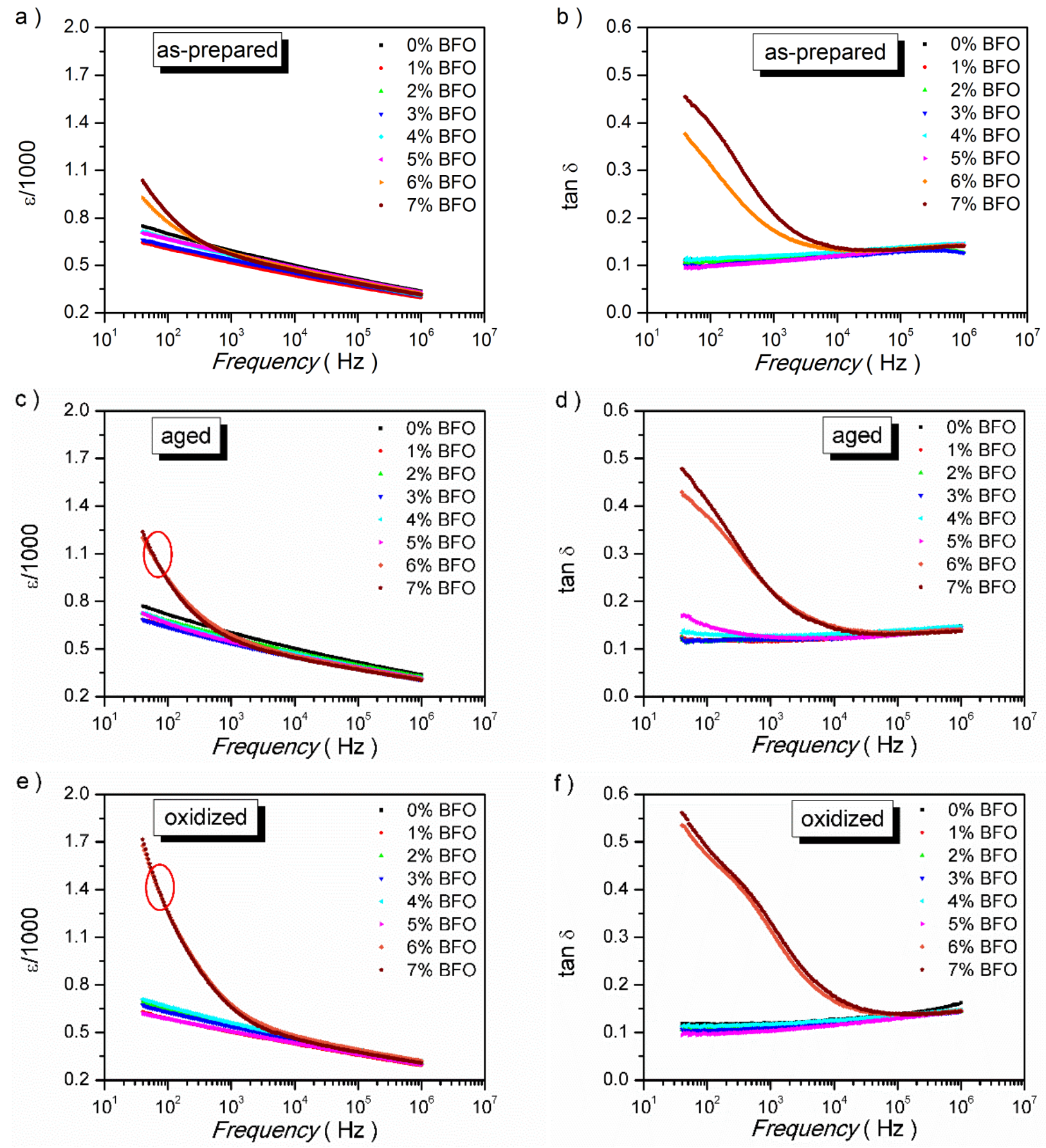

Figure S7 


\title{
Enhanced energy storage performance of (1-x)(BCT-BMT)-xBFO lead-free relaxor ferroelectric ceramics in a broad temperature range
}

\author{
Xu, Mengxing
}

Elsevier

Xu M, Peng B, Zhu J, et al., Enhanced energy storage performance of (1-x)(BCT-BMT)-xBFO lead-free relaxor ferroelectric ceramics in a broad temperature range. Journal of Alloys and Compounds, Volume 789, June 2019, pp. 303-312

https://doi.org/10.1016/j.jallcom.2019.02.314

Downloaded from Cranfield Library Services E-Repository 